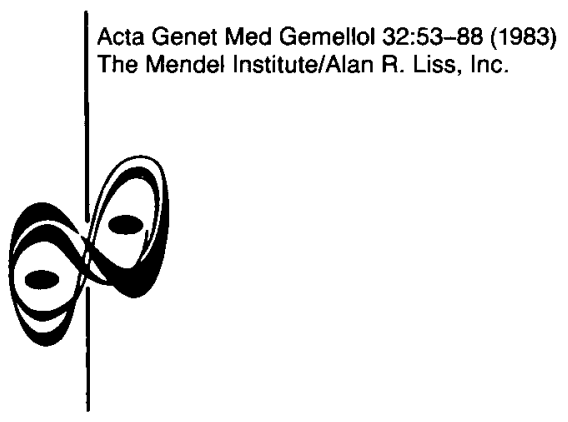

\title{
Twin Research Abstracts 2
}

The following section continues the review of the current literature on twins and twin research announced and started in issue 30:3. This consists in the reproduction of abstracts of publications other than those that have appeared in our journal.

In an effort to offer the most complete coverage possible, a number of complementary though partly overlapping sources of information are being scanned. Also, whereas the single index word "Twins" usually provides only partial coverage, our scanning system involves multiple indicators as well as actual inspection of individual abstracts where appropriate. We shall welcome information from our readers concerning omissions, whenever possible accompanied by the reprint of the omitted article and the authorization to reproduce the abstract.

Our present aim being to provide current information, we have chosen, as a starting date for our scanning process, January 1979, the year in which our journal's new series was started. Since our search is being essentially based on secondary sources, this implies that papers actually published even a few years earlier may occasionally be included. At least for the time being, however, our effort toward complete coverage will concern only the years from 1979 on.

In order to make the scanning easier for our readers, especially in view of the highly interdisciplinary character of twin research, and as first step toward the possible establishment of some information-retrieval system, the following basic classification and coding system has been tentatively adopted:

0 . Twin Biology and Twin Research Methodology

1. Multiple Pregnancy and Twin Care

2. Twin Development and Twin Research in Developmental Studies

3. Twin Research in Cognitive Studies

4. Twin Research in Personality, Psychophysiology, and Psychopathology

5. Twin Research in Substance Exposure and Cotwin Control Studies

6. Twin Research in Physiology and Anthropology

7. Twin Research in Clinical Studies

The abstracts are accordingly subdivided into sections and each abstract is identified by a 5-digit code number (flush left), the first two digits giving the year of publication (of the original article, not of the abstract by the secondary source) and the following three digits giving a consecutive number within the attributed classification group. Title, author(s) with affiliation, reference, and abstract reflect the information provided by the secondary source. (In the case of publications not covered by major secondary sources, however, abstracts will be especially prepared or edited.) 
Covered in this issue are publications dealing with twins and twin research (other than those that have appeared in this journal) abstracted in the year 1979 by the following series of Excerpta Medica (EM): Cancer (C); Cardiovascular Diseases and Cardiovascular Surgery (CD); Chest Diseases, Thoracic Surgery and Tuberculosis (ChD); Developmental Biology and Teratology (DBT); Dermatology and Venereology (DV); Endocrinology (E); Gerontology and Geriatrics (GG); General Pathology and Pathological Anatomy (GP); Human Genetics (HG); Internal Medicine (IM); Immunology, Serology and Transplantation (IST); Ophthalmology (O); Obstetrics and Gynecology (OG); Oto-Rhino-Laryngology (ORL); Physiology (Ph); Pediatrics and Pediatric Surgery (PPS); Radiology (R).

The abstracts are reproduced by permission of the publisher, and this is acknowledged by the source information code preceding (flush right) each individual abstract: For instance, the code EMHG-22-1907 acknowledges that the abstract is No. 1907 in Volume 22 of the Excerpta Medica/Human Genetics and that it is reproduced by permission of the publisher.

\title{
0. TWIN BIOLOGY AND TWIN RESEARCH METHODOLOGY
}

$76-0-01$

EMHG-22-1907

\section{ZYGOSITY AND SECONDARY SEX RATIO ESTIMATES FROM TWIINNING STUDIES ON HUMAN POPULATIONS}

\section{I.T. Cruz}

Department of Epidemiology and Biostatistics, Institute of Public Health, Manila, Philippines Acta Medica Philippina (1976) 1211:33-37

\begin{abstract}
This paper presents further results on the estimation of monozygotic (or dizygotic) twinning frequency and the so-called secondary sex ratio (or sex ratio at birth) from a sample of twin births. The latter is a rather important parameter whose behaviour over time has significant demographic implications. Formulas for the computation of variances and standard errors of the estimates, which are useful in comparative analysis and in the construction of confidence intervals for the above parameters, are developed. Contour plots of the variances in the domain where values of the parameters are liable to be encountered in practice are also given to serve as nomographic aids in the computations.
\end{abstract}

77-0-02

EMHG-22-2395

THE ANALYSIS OF TWIN DATA. APPLICATION TO DERMATOGLYPHICS. II. DISCORDANCE AND ASYMMETRY

\author{
E.R. Iagolnitzer \\ France \\ Biomedicine Humaine (1977) 12:43-58
}

The 'Component Pair Analysis' (CPA), a multivariate method for the analysis of paired data is extended to fourfold observations. In CPA, the data are presented in the form of a 4 block array that holds the information known about the material under study and its analysis accounts for the sum (between pair) and difference (within pair) structures. If the observations on the individuals of a pair are themselves paired observations (a pair has two individuals and each individual has two sides $R$ and $L$ ), they may be regarded as fourfold observations R1-L1-R2-L2 for which three types of internal differences associated to orthogonal contrasts may be defined: discordance $(++--)$, asymmetry $(+-+-)$ and mirror imagery $(+--+)$. In the proposed procedure, a 16 block array $T 16$ is built and it is shown that the analysis of T16 accounts for the sum structure (inter sides) and for the three contrasts. Applied to dactyloglyphic data, directional asymmetry may be taken into account by going through 2 algorithms where only the structure of asymmetry is changed; the difference gives the structure of directional asymmetry. The procedure has been applied to two sets of male twins ( 139 monozygotic, $M Z$, and 92 dizygotic, DZ, pairs), with the following results: the total variances are 713 and 764 for the $\mathrm{MZ}$ and $\mathrm{DZ}$ sets respectively; the variances for $\mathrm{MZ}$ discordance and for $\mathrm{MZ}$ and $\mathrm{DZ}$ fluctuating asymmetry and mirror imagery are similar, each around 30 to 40 points; the 'developmental noise' has the same intensity in MZ and DZ twins, and causes fluctuations of similar intensity between the individuals of a 
$\mathrm{MZ}$ pair and between the sides of an individual; the observed differences between the various variances are in good agreement with theoretical relationships previously established; there is a directional asymmetry (mainly due to finger 1 in males); its variance is around 7 to 8 points in males, slightly lower in females.

78-0-06

EMHG-23-393

\title{
A HUNDRED YEARS OF GEMELLOLOGY
}

\author{
L. Gedda and G. Brenci
}

G. Mendel Institute of Medical Genetics and Gemellology, Rome

Journal de Genetique Humaine (1978) 26:211-223

Over the past hundred years, since Sir Francis Galton first pointed out its scientific value, the study of twins has considerably widened its scope and significance. Gemellology has come to represent an important branch of human genetics and to be applied to the most diverse fields of biomedical and behavioral research, besides obviously contributing to the study of the specific biological, medical, and psychological aspects of the twin condition. More recently, then, it has in turn created a new branch of modern genetic research, chronogenetics. Finally, sponsored and coordinated by the Mendel Institute in Rome, an International Society for Twin Studies has developed.

78-0-07

EMHG-23-2059

\section{PROSPECTS FOR THE APPLICATION OF DENTAL MORPHOLOGY IN TWIN TYPE ANALYSIS}

\author{
A.A. Zoobov and B.A. Nikityuk
}

Institute of Ethnography, USSR Academy of Science, Moscow

Journal of Human Evolution (1978) 7:519-524

\begin{abstract}
The possibility of twin type diagnostic on the basis of the dental morphology (in particular the 'odontoglyphics') is discussed. The distribution of 66 dental characters in 139 pairs of twins ( 54 monozygotic, 85 dizygotic) was studied. Forty-six dental characters were found to display far closer resemblance in the MZ pairs in comparison with DZ pairs, so they can supposedly be applied as additional criteria of the twin type.
\end{abstract}

78-0-08

EMHG-23-2317

\section{TWINNING IN IRAQI POPULATION AND THE SIGNIFICANCE OF A FAMILY WITH HIGH TWINNING RATE}

\author{
W.K. Al-Murrani
}

Department of Veterinary Public Health, College of Veterinary Medicine, Baghdad University, Iraq Iraqi Medical Journal (1978) 26:46-47

The incidence of twinning in a sample of the Iraqi population was found to be $0.78 \%$ or 1 in 128 maternities; of MZ twins 1 in 358 and of DZ twins 1 in 197 births. Twinning rate is close to that reported for Greece and Japan. The incidence of $M Z$ twins out of the total twin bitths was estimated to be $35.6 \%$. The family history with high twinning rate was used to postulate a mode of inheritance in accordance with the bases of inheritance of threshold characters.

78-0-09

EMOG-35-367

\section{ASPECTS OF THE INCREASING TRIPLET RATE IN AUSTRALIA}

\section{C.J. Brackenridge}

Department of Psychiatry, University of Melbourne

Journal of Biosocial Science (1978) 10:183-188

The sex composition of 862 sets of Australian triplets was independent of decade and State of birth the period 1920-69. The triplet rate increased by $40 \%$ during the 50 years in contrast with declining rates reported elsewhere. The increase was due to dizygotic and trizygotic types, together but not individually, and occurred despite an $8.6 \%$ decrease in the average national maternal age over the same period. Adjustment for age led to standardized individual zygosity rates, estimates of which were compared with reported values obtained elsewhere. The dependence of zygosity rates on maternal age was shown to rise progressively as the number of ova released in triplet formation increases. 
MATERNAL AND ENVIRONMENTAL FACTORS AFFECTING TWIN BIRTHS IN CANADIAN CITIES

\author{
J.M. Elwood \\ Cancer Contr. Agency of British Columbia, Vancouver, Canada \\ British Journal of Obstetrics and Gynaecology (1978) 85:351-358
}

\begin{abstract}
Details of 4972 pairs of twins born to mothers resident in 14 large Canadian cities in the years 1952, 1957, 1962, and 1967 were compared to those of a random sample of 4969 single births. Both dizygotic and monozygotic twinning rates, derived by Weinberg's formula, showed increases with both maternal age and with the number of previous livebirths. Dizygotic twinning rates also showed a seasonal variation with an October maximum. Twinning rates were lower in Oriental women, but did not vary between other ethnic groups, or by city of residence, legitimacy, paternal age or maternal history of stillbirths.
\end{abstract}

78-0-11

EMHG-22-742

\title{
SEROLOGIC MARKERS AND CHROMOSOME VARIANTS IN A PAIR OF CHIMERIC TWINS
}

\author{
H.E. Hansen, B. Eriksen, E. Niebuhr, and E. Dabelsteen \\ Anthropology Department, University Institute of Forensic Medicine, University Institute of Medical \\ Genetics, Copenhagen \\ Human Heredity (1978) 28:411-420
}

\begin{abstract}
A pair of chimeric twins, T.S. (male) and M.R. (female) first examined in 1970 are reinvestigated in order to determine if the proportions of admixture of red cells in their blood are unchanged, and if erythrocytes and leukocytes show the same percentage of admixture. T.S., M.R. and their family are investigated for HLA, serum types, and erythrocyte antigens and enzymes. A quantitative determination of 'foreign' cell populations in the blood of each twin is attempted for the systems ABO, and HLA, and for sex chromosomes in PHA stimulated lymphocytes. The results for the ABO system obtained by agglutination technique and by a doublelayer immunofluorescence technique indicate that the population of M.R. erythrocytes in T.S. has decreased during the 7-yr period, and is now below half the size found in 1970. Erythrocytes and leukocytes show the same percentage of admixture in both twins.
\end{abstract}

$78-0-12$

EMOG-35-82

\section{SEASONAL VARIATIONS IN THE INCIDENCE OF THE CONCEPTION OF MULTIPLE PREGNANCIES IN TWO COUNTRIES}

Fr. Hoffmann

Geburtshilfe Gynakol. Abt., Kathol Krankenh St. Joseph, Essen-Werden, Federal Republic of Germany Geburtshilfe Frauenheilkunde (1978) 38:125-130

Seasonal variations in the incidence of the conception of multiple pregnancies are compared in the same population area in two centuries. 12,617 singleton and 101 twin pregnancies from 1803 to 1852 are compared to 63,967 singleton, 473 twin and 5 triplet pregnancies from 1965 to 1970 . In both groups the percentage decrease of multiple conceptions during the first three months of the year was higher than the percentage decrease of singleton conceptions. In both groups the percentage increase of multiple conceptions during the summer months was higher than the percentage increase of singleton conceptions. The question of the influence of light on the hypothalamic-pituitary centres as a cause of the variations in multiple conceptions has decreased since the beginning of the $19 t \mathrm{th}$ century independent of the progress in obstetrics and perinatology. The decreased rate of multiparas and especially older multiparas is suggested as the likely cause for this decrease.

78-0-13

EMHG-23-921

\section{A STUDY OF THE FERTILITY OF MOTHERS OF TWINS}

R.G. Record, E. Armstrong, and R.J. Lancashire

Department of Social Medicine, University of Birmingham, Great Britain

Journal of Epidemiology and Community Health (1978) 32:183-189

Data on all births to Birmingham residents during a ten-year period were used to compare the reproductive history of mothers immediately before and after a twin maternity with that of mothers of similar age and parity 
before and after a single birth. It was found that mothers of twins were less likely than mothers of singletons to have a subsequent birth if both twins survived, but if only one survived there was little difference between the two groups. If both twins died, however, the likelihood of a later birth was increased. The interval before the next birth was longer than expected when both twins survived and much shorter when both died. The sex of the twins appeared to have little influence on subsequent reproduction, in spite of the fact that for singletoncontaining fraternities a further pregnancy was more likely if the first two children were of the same sex than if they were of opposite sexes. The mean interval preceding a twin maternity was almost the same as that preceding a single birth when both twins survived, but it was shorter when one twin died (being similar to that preceding the birth of a singleton who died) and it was much shorter when both twins died.

78-0-14

EMHG-22-405

\section{GENE FREQUENCY FOR SAMPLES OF BLACK AND WHITE TWINS FROM THE PHILADELPHIA METROPOLITAN AREA}

A.J. Pakstis, H.F. Polesky, S. Scarr, and S.H. Katz

Dight Institute, University of Minnesota, Minneapolis

Human Genetics (1978) 43:159-177

Maximum likelihood estimates of gene frequencies and their standard errors are presented for 21 blood group and serum protein polymorphisms. The observed frequencies for certain high and low frequency antigens also are reported. The data come from a sample of 399 same-sex twin pairs and 2 sets of triplets from the Greater Philadelphia urban region encompassing roughly 5 counties in southeastern Pennsylvania and 3 counties of southern New Jersey. Analyses are carried out separately for the 4 subgroups created by subdividing the sample by race and co-twin. Total sample estimates are also calculated within the 2 socially defined racial groups. The gene frequency estimates generally appear to be consistent with previously reported data for U.S. urban populations. The frequency of the Fy allele in the Duffy system, however, seems to be the highest value thus far published for a white population. The white sample Fy allele very well may be a heterogeneous class in which only a very small fraction is comparable to the Fy allele common in the black sample.

78-0-15

EMHG-23-2051

HUMAN TRIPLETS: CHROMOSOMAL POLYMORPHISM AND ZYGOSITY DIAGNOSIS

U. Friedrich

Institute of Human Genetics, University of Aarhus, Denmark

Hereditas (1978) 89:264-267

The various staining methods have found many useful applications in human cytogenetics. Q and $\mathrm{C}$ banding turned out to be a valuable help in zygosity diagnosis. A case of triplets is presented, to further emphasize the usefulness of the above methods in zygosity diagnosis.

78-0-16

TWINS AND Q-BANDED CHROMOSOME POLYMORPHISMS

EMHG-23-1212

A.A. McCracken, P.A. Daly, M.R. Zolnick, and A.M. Clark

School of Life Health Science, University of Delaware, Newark

Human Genetics (1978) 45:253-258

Q-banded chromosomal analyses were performed on 24 pairs of twins to determine the stability and heritability of chromosome polymorphisms, and to establish the use of these markers in the determination of twin zygosity. Sixteen twin pairs were determined monozygotic by chromosome polymorphism analysis and confirmed monozygotic by blood group genotyping. No two genetically distinct individuals had the same polymorphic pattern, suggesting the individuality of each morphological karyotype. The frequencies for the various types of chromosome polymorphisms, including stalk length variations, were determined. Analysis of frequency distribution for variant combinations showed random association. 


\title{
CONJOINED TWINS
}

\author{
J.R. Doig and T.C. Svensen
}

Christ Church Women's Hospital, Christ Church, New Zealand

Australian and New Zealand Journal of Obstetrics and Gynaecology (1978) 18:215-217

A case of thoracopagus conjoined twins is described in which ultrasonography was helpful in achieving an antenatal diagnosis and in allowing consultative decision on management.

78-0-18

EMOG-35-941

\section{CONJOINED TWINNING IN SWEDEN}

B. Kallen and G. Rybo

Department of Embryology, University of Lund, Sweden

Acta Obstetricia et Ginecologica Scandinavica (Stockholm) (1978) 57:257-259

A small 'epidemic' of conjoined twinning is reported occurring at the Skovde Central hospital in 1975-76. 3 pairs were observed; the annual birth number is 2,300. During a $10-y$ r period, 10 cases of conjoined twinning were reported to the Register of Congenital Malformations in Sweden, indicating a probable incidence of 1:75,000 births. These 10 cases were distributed all over the country. Interviews with the 3 women who gave birth to the Skovde conjoined twins revealed no common factor which could be of etiological significance.

78-0-19

EMCD-30-2003

CONGENITAL ABSENCE OF THE HEART: OBSERVATION OF HUMAN

FUNICULOPAGOUS TWINNING WITH INSERTIO FUNICULI FURCATA, FUSION, FORKING, AND INTERPOSITIO VELAMENTOSA

\author{
P. Averback and F.W. Wiglesworth \\ Department of Pathology, McGill University, Montreal \\ Teratology (1978) 17:143-150
}

\begin{abstract}
An anatomic and radiologic study of a normal and acardius twinning with a single placenta is presented with literature review. The fetus was unusually well-developed with an almost normal skeletal and brain formation, a normal genito-urinary tract, and an absence of liver, spleen, lungs, and pancreas. The heart was absent, but the great arteries, single aorta, and veins were present. The placentation is described as funiculopagous with insertio funiculi furcata, fusion, forking and interpositio velamentosa, and the latter may account for the fusion of the two circulations in this instance, with the possibility that the heart was never present. The present and other observations of funucilopagous twins with two amniotic sacs suggest that the forked cord twin anomaly may occur earlier than generally recognized.
\end{abstract}

78-0-20

EMHG-22-227

\section{ANENCEPHALY AND UNILATERAL CLEFT LIP AND PALATE IN CONJOINED TWINS}

\section{U. Rowlatt}

Department of Pathology, Abraham Lincoln School of Medicine, University of Illinois Medical Center, Chicago

Cleft Palate Journal (1978) 15:73-75

Twin girls attached along the thorax and upper abdomen to the level of the umbilicus and possessing apparently one anencephalic head were born to a 28 -year-old Puerto Rican woman at 33 weeks of gestation. There was a complete right unilateral cleft lip and palate.

78-0-21

EMR-41-1094

\section{RARE OCCURRENCE OF A HOLOACARDIOUS ACEPHALIC MONSTER: SONOGRAPHIC AND PATHOLOGIC FINDINGS}

\author{
C. Lehr and J. DiRe \\ Roosevelt Hospital, New York \\ Journal of Clinical Ultrasound (1978) 6:259-26I
}

Sonography is gaining increasing importance in the diagnosis of anomalies in utero. Findings such as anencephaly, hydrocephaly, sacrococcygeal teratoma, fetal ascites, and obstructive uropathy have been described. 
Detection of anomalies such as these are important in the management of the pregnancy and aid in the preparation for the postnatal care or treatment of the fetus. While this article deals with the dramatic findings of a grossly anomalous fetus of a twin pregnancy, the ultimate value of ultrasound is its potential for detecting correctable malformations in a safe, noninvasive and harmless manner.

78-0-22

IS SEPARATION OF STERNOPAGUS CONJOINED TWINS POSSIBLE?

EMPPS-41-1577

\author{
P. Gross \\ Central Hospital St.-Denis, Saint-Denis, France \\ Chirurgie Pediatrique (1978) 19:283-286
}

The case is reported of female sternopagus conjoined twins. One appeared normal; the other presented spina bifida with hydrocephalus. Separation was not made. Embryological study and postmortem findings demonstrate the actual impossibility of separation of sternopagus conjoined twins.

\title{
THE DOMINICAN REPUBLIC CONJOINED TWINS: ISCHIOPAGUS, TETRAPUS, OMPHALOPAGUS
}

H.K. Rosenberg, T.J. Spackman, and A. Chait

Department of Radiology, Childrens Hospital, Philadelphia

American Journal of Roentgenology (1978) 130:921-926

\begin{abstract}
Alta and Clara, the Dominican Republic conjoined twins (ischiopagus, omphalopagus, tetrapus) were evaluated prior to separation with plain films, vaginograms, arteriograms, intravenous pyelogram, barium enema, and upper gastrointestinal series with small bowel follow-through. The clear demonstration of their internal anatomy allowed the surgeons to plan the operative approach and to make a reasonable judgment regarding viability of each baby. Each twin had a semicircular pelvis which joined the other to form a complete ring. There were a few hepatic arterial twigs from Alta which crossed the midline, proving at surgery to be a small bridge of tissue connecting the two livers. Clara's superior mesenteric arteries supplied the majority of the small bowel. Portal venous drainage was separate for each twin. Each baby had two kidneys in normal position with the bladders laterally placed. Each bladder received one ureter from each twin. Two separate small bowels joined proximal to the single colon which terminated in an anus related to Clara's pelvic structures. Following separation, each baby did well. Their postoperative anatomy is described.
\end{abstract}

AN ATTEMPT TO SEPARATE XIPHOPAGUS TWINS SHARING A COMMON HEART, LIVER, AND DUODENUM

J.L. Micheli, H. Sadeghi, J. Freeman, et al.

University Central Hospital, Vaudois, Lausanne, Switzerland

Journal of Pediatric Surgerv (1978) 13:139-142

An attempt was made to separate 7-wk-old conjoined twins. It proved unsuccessful because of extensive cardiac malformations in the shared heart. Details of operation and postmortem findings are described.

THE HUMAN X-CHROMOSOME AND THE LEVELS OF SERUM IMMUNOGLOBULIN M

V. Escobar, L.A. Corey, D. Bixler, et al.

Department of Oral-Facial Genetics, Indiana University Medical Center, Indianapolis

Clinical Genetics (1979) 15:221-227

The serum concentrations of immunoglobulins $\mathrm{G}, \mathrm{A}$ and $\mathrm{M}$ were measured in a sample of 93 pairs of monozygotic twins, their spouses, and their offspring. The hypothesis that the human X-chromosome carries genes which control the levels of immunoglobulin $M$ was tested with three different approaches. Our results indicate that environmental factors are primarily responsible for the observed variation in the levels of IgG and IgA. The variance of IgM seems to be mostly the result of X-linked gene effects, with women having higher IgM levels than men. 


\title{
THE SEX RATIO IN ANENCEPHALY
}

\author{
W.H. James
}

Galton Laboratory, University College, London

Journal of Medical Genetics (1979) 16:128-133

A review of the data supports the suggestion of Knox (1974) that the sex ratio and incidence of anencephalics vary together within populations, as they are to do between populations. There seems some doubt, though, whether Knox was correct in hypothesising that the sex ratio of anencephalics varies with their incidence in relation to the dizygotic twinning rate. The pattern of variation seems to suggest that there are two sorts of cause of anencephaly, one of which is environmental and affects predominantly female embryos. The other may be environmental or genetic. and seems to attack the sexes in roughly equal numbers. If this hypothesis were correct, it would carry implications for the testing of specific teratogens.

\section{MULTIPLE PREGNANCY AND TWIN CARE}

76-1-01

EMOG-35-2607

\section{ENDOCRINOLOGY OF GESTOSIS}

\author{
A.A. Bravo \\ Division Est. Sup., Fac. Med., UNAM, Mexico City \\ Ginecologia y Obstetricia de Mexico (1976) 39:235-246
}

The endocrinologic aspects of gestosis are moving from the speculative field to the scientific one: it seems that progress is being made in research on gestosis etiology. Most probably gravidic hyperemesis is related to high chorionic gonadotropin levels, as in hydatidiform mole and multiple pregnancy; a decreased level of pregnanediol and estriol, may be present also, and a raise in ACTH as well. So, maybe this syndrome could be identified as the adaptation of the general syndrome. Utero-placentary ischemia seems to be an important etiologic factor in gravidic toxemia. since some studies have shown that blood flow may be reduced to $50 \%$ in cases of preeclampsia. Uterine renin is not a direct etiologic factor in toxemia and the same could be said about aldosterone. Estriol levels are very important to evaluate fetal status and an important fall would indicate pregnancy termination, if the fetus is viable. Human chorionic somatotropin is useful to judge feto-placentary sufficiency in preeclampsia.

77-1-01

EMOG-35-730

\section{FETAL LOSS, TWINNING AND BIRTH WEIGHT AFTER ORAL-CONTRACEPTIVE USE}

\author{
K.J. Rothman
}

Department of Epidemiology, Harvard School of Public Health, Boston

New England Journal of Medicine (1977) 297:468-471

To evaluate the effect of oral-contraceptive use on subsequent offspring, the authors previewed information on the pregnancies of 19,887 women who indicated, in response to a mail questionnaire, that they had used oral contraceptives. The rates of spontaneous abortion and stillbirth were smaller for former users than for nonusersa finding consistent with previous studies. Twinning was more frequent among births of infants conceived soon after cessation of oral contraceptives, the rate being approximately twice the expected value for women who had used oral contraceptives for more than six months $(P=0.1$ ). The sex distribution of the twins indicated that the increase was mainly in dizygous twins $(P=0.02)$, in accordance with predictions about increased twinning after cessation of oral contraceptive use. No relation was evident between oral contraceptive use and birth weight.

77-1-02

EMOG-36-86

\section{PREGNANCY AND TWIN DELIVERY}

R. Mingeot, M. Hanssens, and R. Vandervellen

Service Gynecologique, Clinique St.-Michel, Brussels

Journal de Gynecologie, Obstetrique et Biologie de la Reproduction (Paris) (1977) 6:633-660

Twinning is, especially for the newborn, a risk that shows up not only in the figures of perinatal mortality, but when the functional state of the infant is assessed at birth and in later development. The authors recall classical 
ideas about the division of twin pregnancies into monozygotic and dizygotic and the significance of types of placentation. The fetal risk from the point of view of physiopathology in twin pregnancy is linked to 3 factors: lack of room in the uterus, insufficient blood supply through the utero-placental site, and the inadequacy of the cardio-vascular system to adapt itself to the twin pregnancy. These are the factors that are responsible for the prematurity and inadequate growth that affect twins. The problems that arise in caring for twin pregnancies are as a result summarized; the importance of early ultrasonic routine diagnosis is emphasized and so is rest from the 27th and sometimes even the 24th week. After reviewing the classical features concerned with twin delivery the authors emphasize the importance of cardio-tocographic monitoring. In their series of 112 consecutive twin pregnancies, mortality dropped from 6 to 3 per cent thanks on the one hand to systematic ultrasonic diagnosis and monitoring and on the other hand freer indications for performing Caesarean sections. These results are similar to those of $\mathrm{Ho}$ and $\mathrm{Wu}$ who decreased their mortality from 8.5 to 3.9 per cent by using cardio-tocographic control in 36 per cent of their cases. Finally, tracings of cardio-tocographic records are given together with a summary of a manual for the operative management of these cases for both the first and the second twin.

77-1-03 EMOG-35-83

\title{
ALPHA-FETOPROTEIN (AFP) LEVELS IN MATERNAL SERUM IN EARLY MULTIPLE PREGNANCIES
}

\author{
G. Lidbjork, B. Kjessler and G.B.O. Johansson
}

Department of Obstetrics and Gynecology, University Hospital, Uppsala, Sweden

Acta Obstetricia et Gynecologica Scandinavica Supplement (Stockholm) (1977) 56/suppl. 69:45-49

General application of hPL or CAP determinations in maternal serum samples in order to preselect potentially multiple pregnant women for further examination, e.g., by ultrasonography, implies the introduction of additional screening programs for specific and restricted clinical purposes. The same information may, however, be obtained as a spin-off result from general screening programs for maternal serum AFP levels during the 14th-20th postmenstrual week, which in turn aim to recognize a variety of severe fetal defects and general pregnancy disorders.

\section{SUPERFOETATION: A DEBATED QUESTION. NOTES ON A SUGGESTIVE CASE OF TWIN PREGNANCY}

\author{
C. Angeloni
}

Divizione di Ostetricia e Ginecologia. Ente Ospedale Prov. San Liberatore, Atri, Italy

Minerva Ginecologica (1978) 30:549-550

Since uterine malformation was not involved, marked disparity of development in the offspring of a twin pregnancy was indicative of superfoetation. The relevant literature is briefly reviewed.

\section{TRIPLET PREGNANCY}

\author{
E. Daw
}

North Manchester General Hospital, Great Britain

British Journal of Obstetric's and Ginaecology (1978) 85:505-509

A series of 14 triplet pregnancies has been analyzed. The older triplet mother had a better chance of fetal survival than the younger mother. Parity did not appear to have much effect on fetal survival but the maturity of the infants at birth had more influence than did birth weight, on their survival. The interval between the delivery of the second and third infants did not correlate with the poor prognosis for the last infant. Spontaneous breech delivery appeared to have a worse prognosis than assisted breech delivery. There was a high incidence of girls and they appeared to do better than the boys. There was a high incidence of monozygotic twin pairs in these triplet pregnancies. 
78-1-03

EMOG-35-944

MATERNAL SERUM ALPHA-FETOPROTEIN LEVELS IN TRIPLET AND QUADRUPLET PREGNANCY

N. Wald, H. Cuckle, and G. Stirrat

DHSS Cancer Epidemiology Clinical Trials Unit, Department of Medicine, Radcliffe Infirmary, Oxford, Great Britain

British Journal of Obstetrics and Gynaecology (1978) 85:124-126

Maternal serum alpha-fetoprotein (AFP) levels were higher in 6 triplet pregnancies and 3 quadruplet pregnancies than in control singleton pregnancies matched for maternal age, parity and time of gestation at which the serum sample was taken. Between 12 and 23 wk of pregnancy, the average AFP levels among the triplet pregnancies was 3 times that found in the singleton pregnancies, and the level in the quadruplet pregnancies was even higher. Maternal serum AFP levels appear to be associated with the number of fetuses in utero.

78-1-04

\section{OCTUPLET PREGNANCY FOLLOWING GONADOTROPHIN TREATMENT}

EMOG-35-942

W. Moebius and W. Carol

Frauenklin., Berlin Med., Friedrich-Schiller University, Jena, German Democratic Republic

Zentralblatt für Gynaekologie (1978) 100:575-578

Report on a case of an octuplet pregnancy induced by gonadotrophin therapy. This pregnancy terminated in abortion during the 6th month.

78-1-05

\section{A HYPOTHESIS FOR HIGH MULTIPLE PREGNANCIES AFTER CLOMIPHENE}

EMOG-36-1779

D.L. Healy and H.G. Burger

Medical Research Center, Prince Henry's Hospital, Melbourne

Australian and New Zealand Journal of Obstetrics and Gynaecology (1978) 18:242-246

A triplet and a quadruplet pregnancy following induction of ovulation with clomiphene are described; in each patient secondary amenorrhoea followed oral contraceptive use and several anovulatory or inadequate menstrual cycles had occurred on initial clomiphene therapy. Conception occurred in the first cycle after increasing drug dosage or the addition of human chorionic gonadotrophin (HCG) to the treatment regimen. The authors suggest, in explanation of these pregnancies, that repeated suboptimal stimulation of the ovaries as a result of clomiphene therapy develops several follicles to a critical stage; a subsequent greater ovulatory stimulus allows for synchronous development of several large follicles and multiple ovulation.

78-1-06

\section{INTRAUTERINE BREATHING MOVEMENTS AND FETAL PRESENTATION}

EMOG-35-108

K. Marsal, G. Gennser, and S. Kullander

Department of Obstetrics and Gynecology, Malmo General Hospital, University of Lund, Sweden

Obstetrics and Gynecology (1978) 51:163-165

Fetal breathing movements in 14 twin pregnancies were examined with ultrasonic technique. The twin fetuses I in cephalic presentation showed a significantly higher percentage of apnea and periodic breathing compared with twin fetuses 1l. No such difference was found in twin pairs with Twin $I$ in breech presentation. Also in the control group of 27 singleton pregnancies, the fetuses in cephalic presentation had a higher incidence of apnea and periodic breathing than those in breech presentation. The position of the fetus seems to be decisive for the character of the breathing movements before birth.

78-1-07

EMOG-36-2634

\section{A SURVEY OF 59 TRIPLET PREGNANCIES}

D. Itzkowic

Queen Charlotte's Maternity Hospital, London

British Journal of Obstetrics and Gynaecology (1979) 86:23-28

The outcome of 59 triplet pregnancies from four hospitals was analyzed. The combined stillbirth and neonatal mortality rate was $232 / 1000$. Preterm labour and birth order were the most important identifiable factors in 
relation to neonatal death. Birth weight within a triplet set and malpresentation were not related to neonatal death. Elective cervical suture appeared to be of no value in prolonging gestation.

78-1-08

EMOG-35-109

\title{
RAPID B SCAN (REAL TIME) ULTRASONOGRAPHY IN THE IDENTIFICATION AND EVALUATION OF TWIN PREGNANCIES
}

\author{
S.C. Levine and R.A. Filly
}

Cardiovascular Research Institute, University of California, San Francisco

Obstetrics and Gynecology (1978) 51:170-172

Real-time ultrasonography utilizing a handheld linear array transducer provides a highly accurate method of identifying and evaluating the twin gestation. The rapidity of real-time scanning eliminates interpretational problems caused by fetal movements. Additionally, the versatility of transducer positioning facilitates recognition of appropriate fetal planes for assessment of viability and growth. A prospective study of 595 consecutive pregnancies yielded no misdiagnoses of the number of fetuses present and only one false positive diagnosis of fetal viability.

78-1-09

EMOG-35-1518

\section{VALUE OF ULTRASONIC EXAMINATION IN OBSTETRICS}

V. Sadauskas

Frauenklin., Institute of Medicine, Kaunas, Soviet Union

Zentralblatt für Gynaekologie (1978) 100:1051-1052

We have improved our perinatal mortality and morbidity by investigations by way of an ultrasonic A-Scan device. Especially important were the diagnosis of twins, calculation of the fetal weight and the localisation of the placenta.

78-1-10

EMPPS-40-3419

\section{DETERMINATION OF THE GESTATION PERIOD BY MEANS OF ULTRASOUND. CEPHALOMETRY IN TWINS}

W. Lichtenegger, P.A.M. Weiss, and R. Kometter

Geburtshilfe Gynakol., Univ. Klin., Graz, Austria

Zeitschrift für Geburtshilfe und Perinatologie (1978) 182:122-124

In 147 twin pregnancies, the biparietal diameter of the skull was determined by means of an ultrasound B-scan method. 574 individual measurements were evaluated. It was found that a marked flattening of the growth curve sets in from the 30 th week of pregnancy, compared with single births. The difference amounted to 6 $\mathrm{mm}$ in the 40 th week of pregnancy. The wavy shape of the mean value curve in twins up to the 30 th week of pregnancy appears particularly remarkable. The reason for this phenomenon could be seen in high-grade placental insufficiency causing spontaneous abortion or premature delivery. Accordingly, an increased incidence of abortion was recorded in the $21 \mathrm{st}$ and 25 th week, as well as a peak in premature births in the 29 th and 30 th week of pregnancy. The heads of the twins were not equal in size. The average difference of the diameters of the skull was $6 \mathrm{~mm}$.

78-1-11

EMOG-36-2077

\section{PREVENTION OF PREMATURITY IN TWINS}

R.L. Tamby Raja, V. Atputharajah, and Y. Salmon

Kandang Kerbau Hospital, Singapore

Australian and New Zealand Journal of Obstetrics and Gynaecology (1978) 18:179-181

Prematurity remains a major hazard of twin pregnancy. This study suggests that the prophylactic use of a powerful beta-adrenergic drug in twin pregnancy can be of twofold benefit. First, the tocolytic effect of this drug in the dosage described inhibits uterine activity and significantly prolongs pregnancy. Second, and perhaps more important, are the haemodynamic and metabolic effects of therapy resulting in improved growth and increased fetal weight. 


\title{
SALBUTAMOL THERAPY FOR THE PREVENTION OF PREMATURITY IN TWINS
}

\author{
R.L. Tamby Raja and Y. Salmon \\ Kandang Kerbau Hospital, Singapore \\ IRCS Medical Science and Clinical Medicine (1978) 6:91
}

\begin{abstract}
This study suggests that the prophylactic use of a powerful $\beta$ adrenergic drug in pregnancy can be of two-fold benefit. Firstly, the tocolytic effect of this drug in the dosage described inhibits uterine activity and significantly prolongs pregnancy. Secondly, and perhaps more important, are the haemodynamic and metabolic effects of therapy resulting in improved growth and increased fetal weight. Morris has demonstrated decreased uterine blood flow in twin pregnancy which may account for the high incidence of fetal growth retardation in twins. Further studies should be performed to elucidate the mechanisms of action of $\beta$ adrenergic compounds on the developing fetus so that this growth promoting effect of salbutamol may be used to advantage.
\end{abstract}

78-1-13

EMOG-36-419

\section{CLINICAL ASPECTS OF PREMATURITY IN TWIN DELIVERY}

H. Sawa, K. Gorska, K. Kotzbach, and A. Dziewiatkowska

Klin. Polozn. Chor. Kob., AM. Gdansk, Poland

Ginekologia Polska (1978) 49:879-884

In 32,752 deliveries between 1968 and 1976. 316 were twin pregnancies and labors. These were submitted to clinical analysis for establishment of incidence of prematurity, neonatal and fetal perinatal mortality rate of prematurely delivered twins, percentage of mortality in weight groups and causes of mortality. The mortality rate of preterm twins was $21 \%$, and was six times as great as the mortality rate of term twin deliveries $(3.4 \%)$. The perinatal mortality rate of twins was weight-dependent. In the weight group of $1000 \mathrm{~g}$ the mortality was almost $100 \%$; in the ranges 1001-1500 it was 50.92\%, 1501-2000 15.99\%, and 2001-2200 4.4\%. The main cause of neonatal or fetal deaths in premature twin deliveries was the respiratory distress syndrome. The deaths mainly affected the second twin $(60.9 \%$ of the mortality rate of twins with weight-at-delivery above $1001 \mathrm{~g})$. The higher incidence of mortality of the second twin was due to the more frequent occurrence of the respiratory distress syndrome in the second twin.

\section{8-1-14}

EMOG-35-2290

\section{DELAYED INTERVAL DELIVERY OF A TWIN PREGNANCY}

\author{
R.J. Thomsen
}

97th General U.S. Army Hospital, Frankfurt, Federal Republic of Germany

Obstetrics and Gynecology (1978) 52(suppl 1):37s-40s

A twin pregnancy is reported in which a prolonged interval between delivery of twins was accomplished by the use of labor-inhibiting drugs and the placement of a cervical cerclage. Infants weighing 690 and $1192 \mathrm{~g}$ were delivered from a mother with a normal uterus at 27 and 31 wk gestation; with survival of the second twin. Pathologic and sonographic findings in the case, philosophies of its management, and a review of the medical literature are presented. The case is apparently unique to obstetric literature.

$78-1-15$

EMOG-35-361

HUMAN PLACENTAL LACTOGEN, ESTRADIOL-17 $\beta$, AND PROGESTERONE LEVELS IN THE THIRD TRIMESTER AND THEIR RESPECTIVE VALUES FOR DETECTING TWIN PREGNANCY

S. Batra. N.O. Sjoberg, and A. Aberg

Department of Obstetrics and Gynecology, University Hospital, Lund, Sweden

American Journal of Obstetrics and Gynecology (1978) 131:69-72

Plasma levels of HPL, P, and E2 was serially measured between weeks 30 to 36 in simplex and duplex pregnancies. Levels of both HPL and P were significantly higher in duplex than in simplex pregnancies. However, this was not the case for E2. There was a significant correlation between HPL and P levels. It is indicated that measurement of plasma P levels, as those of HPL levels, but not E2 levels is of value for detecting twin pregnancy. 


\title{
THE SECOND TWIN
}

J. Richon, P. Landes, D. Perrin, and M. Schweitzer

Clinique Obstétrique, Nancy, France

Annales de Médicine (Nancy) (1978) 17:531-538

The study of 161 files of twin pregnancies at the Maternite Régionale of Nancy permits us to point out the causal factors of perinatal death in twins, and in particular of the higher rate of death of the second twin. In twin pregnancies, the rate of perinatal death is six times higher than in the general population (139\% instead of $22.2 \%$ ). Stillbirth and neonatal death rates are affected, one as unfavourable as the other. The higher death rate of the second twin is considerable (186\% instead of $93 \%$ ). There are certain unfavourable factors for the perinatal prognosis of the two twins: parity, complications of the pregnancy, the delay in diagnosing the twin pregnancy, and especially the fact that half of these pregnancies deliver prematurely. The higher death rate of the second twin is linked to the difficulty of in utero surveillance, to the frequency of malpositions and of assisted deliveries. The longer the time lapse between the two births, lesser are the chances of the normal survival of the second twin. The bringing to light of these particular factors of risk allows us to point out certain points of therapeutic conduct and to suggest preventive measures

$78-1-17$

EMPPS-40-3087

\section{SERUM ALPHAFETOPROTEIN IN MULTIPLE PREGNANCY}

\author{
E.M. Bryan, R.W. Thorp, and E. Nicholson
}

Department of Paediatrics and Neonatal Medicine, Hammersmith Hospital, London

Biology of the Neonate (1978) 34:40-47

The concentration of $\alpha$-fetoprotein (AFP) was determined in paired umbilical cord and maternal sera in 42 multiple pregnancies. No concentrations above $1.4 \mu \mathrm{g} / \mathrm{ml}$ were detected in maternal sera. Although there was a significant inverse correlation between cord AFP levels and gestational age, large intrapair discrepancies were common and these were not influenced by birth order, weight, or malformations. Intrapair AFP ratios were higher amongst dizygotic than monozygotic twins. In a pair discordant for neonatal hepatitis, the affected twin had the lower level of AFP in cord serum, but AFP was still detectable at 55 days.

78-1-18

EMHG-22-730

THE SIGNIFICANCE OF RAISED MATERNAL PLASMA ALPHA-FETOPROTEIN IN TWIN PREGNANCY

Z. Keilani, P.C. Clarke, M.J. Kitau, and T. Chard

Department of Reproductive Physiology, St. Bartholomew's Hospital Medical College, London

British Journal of Obstetric's and Gynaecology (1978) 85:510-511.

A hundred twin pregnancies were examined before $27 \mathrm{wk}$ gestation. The level of maternal plasma alphafetoprotein (AFP) was correlated with outcome of the pregnancy. Forty per cent of all women had elevated plasma AFP levels. At birth the combined infant weights were greater in the women with elevated AFP; the gestational age at delivery was unrelated to the level of AFP in early pregnancy.

78-1-19

EMOG-35-2340

\section{HUMAN PLACENTAL LACTOGEN LEVELS IN MULTIPLE PREGNANCIES}

W.N. Spellacy, W.C. Buhi, and S.A. Birk

Department of Obstetrics and Gynecology, University of Florida College of Medicine, Gainesville

Obstetrics and Gynecology (1978) 52:210-212

Serum human placental lactogen (hPL) levels were measured in duplicate with a radioimmunoassay in 206 serum samples at 30 and 36 weeks' gestation from women with normal singleton pregnancies (75) or pregnancies with twins (37). One triplet pregnancy was also studied. The results show a significant elevation of hPL in the women with twin pregnancies at both the $30 \mathrm{th}(7.0 \mathrm{vs} 6.0 \mu \mathrm{g} / \mathrm{ml})$ and the $36 \mathrm{th}(9.2 \mathrm{vs} 7.4 \mu \mathrm{g} / \mathrm{ml})$ weeks. Onethird of the twin pregnancies had values of hPL in excess of $8.0 \mu \mathrm{g} / \mathrm{ml}$ at 30 weeks and more than half had values in excess of $9.0 \mu \mathrm{g} / \mathrm{ml}$ at 36 weeks. The triplet pregnancy had an hPL value of $11.0 \mu \mathrm{g} / \mathrm{ml}$ at 36 weeks' gestation. These data support the potential usefulness of serum hPL measurements in the screening profile for the detection of high-risk pregnancies 


\section{COMPONENTS OF THE HEMOSTATIC MECHANISM IN TWIN PREGNANCY}

R. Condie and D. Campbell

Department of Obstetrics, University of Aberdeen, Great Britain

British Journal of Obstetrics and Gynaecology (1978) 85:37-39

Components of the hemostatic mechanism were measured at intervals throughout pregnancy in 11 patients with twins and compared with a group of 21 patients with singleton pregnancies. Mean plasma fibrinogen levels were consistently (but not significantly) elevated in the mothers of twins while other parameters showed no differences.

78-1-21

EMOG-36-129

\section{BREECH DELIVERIES IN SERIES}

G. Heluin, H. Hajeri, and E. Papiernik

Maternité Hôpital Antoine Beclere, Clamart, France

Journal de Gynecologie, Obstétrique et Biologie de la Reproduction (1978) 7:975-986

In this study, after reviewing the opinions and results in the literature, the authors studied the 300 first-time breech deliveries in series occurring in the maternity ward of the Antoine Beclere hospital at Clamart, classifying them in different categories: term, hypotrophic, premature, and multiple pregnancy; the latter two associated risks are emphasized as the most important. It appears that normal delivery, when well chosen, is possible for babies of normal weight. while knowing that a caesarian section may be necessary at the least labor anomaly. Caesarian section should not be applied systematically on term breeches if obstetrical explorations are normalin these cases $60 \%$ of labors perform well with a minimal morbidity and a mortality of no importance. On the contrary, the 3 other categories are at high risk and should profit systematically from a caesarian section. However, the criteria of hypotrophy are difficult to confirm, limiting somewhat for the present the scope of this measure.

78-1-22

EMHG-23-2265

\section{EARLY AMNIOCENTESIS IN TWIN PREGNANCIES}

R. Henrion, F. Papa, J.L. Rouvillois, and J.P. Aubry

Service Gynecologique et Obstetrique, Maternité Port Royal, Paris

Nouvelle Presse Medicale (1978) 7:4119-4121

Since 1972, we have performed 951 early amniocenteses, in 902 pregnant women. There were 19 twin pregnancies, all dianniotic, representing $2.1 \%$ of the sample. Diagnosis was always suspected before the amniocentesis. It was confirmed by echography in the 14 cases in which this technique was used. Out of the first 5 cases without echography, we punctured only one sac. In the 14 last cases, the process was successful in 13 cases thanks to:-the perfection of echography showing the exact location of the fetuses and the position of the septum-the injection of congo red ( 12 cases) or methylene blue ( 2 cases) into the first sac. The indications were as follows: chromosomal aberrations ( 14 cases), metabolic diseases ( 1 case), sex linked disorders ( 1 case), neural tube defects ( 3 cases). No complications due to amniocentesis were observed but three abortions and one fetal death occurred. The reason why is discussed. We have made only one therapeutic abortion.

78-1-23

EMOG-35-2329

\section{UNCONJUGATED ESTRIOL AND CORTISOL IN MATERNAL AND CORD SERUM AND} AMNIOTIC FLUID IN NORMAL AND ABNORMAL PREGNANCY

J.W. Goldkrand

Department of Obstetrics and Gynecology, University of Nebraska Medical Center, Omaha Obstetrics and Gynecology (1978) 52:264-27I

Study was made of unconjugated estriol (E) by radioimmunoassay and cortisol (C) by competitive proteinbinding assay in the maternal serum (Mat), mixed cord blood (Cord), and amniotic fluid (AF) from 50 pregnancies, 37 or more weeks' gestation (30 normal women, 9 insulin-dependent diabetics; 8 with chronic stress: preeclampsia, eclampsia; 3 sets of uncomplicated twins). The normal patients' results were suggestive that Cord $\mathrm{E}$ and $\mathrm{C}$ were derived from a common precursor or fetal organ activity $(\mathrm{r}=0.382, \mathrm{P}<0.05)$ and 
that Mat $\mathrm{E}$, which correlated with Cord $\mathrm{E}(\mathrm{r}=0.432 . \mathrm{P}<0.05)$, reflected fetoplacental metabolism. Within 1 hour of delivery, Mat $\mathrm{E}$ dropped to $<2.0 \mathrm{ng} / \mathrm{ml}$. Insulin-dependent diabetics had values similar to those in the normal population. In chronically stressed patients, the results suggest that stress causes fetal $\mathrm{C}$ production to increase relative to $\mathrm{E}$. The Mat $\mathrm{E}$ (mean value, $6.18 \pm 1.23 \mathrm{ng} / \mathrm{ml}$ ) was significantly less than normal $(\mathrm{P}<0.01$ ), while the Cord $\mathrm{C}$ (mean value, $35.4 \pm 4.5 \mu \mathrm{g} / \mathrm{dl}$ ) was greater than in the normal baby $(\mathrm{P}<0.01)$. Twin pregnancies demonstrated elevated Mat E, but individual Cord $\mathrm{E}$ approximated the normal singleton. Paired sample mean ratios of $\mathrm{E}$ and $\mathrm{C}$ in the various compartments were utilized to differentiate groups of patients. The Mat E/AF E and Mat C/AF E gave meaningful differences that could be clinically useful because of the availability of sampling. The biosynthetic pathways of $E$ and $C$, the metabolic and compartmental interrelationships, and the control mechanisms are discussed and related to the data.

78-1-24

EMHG-22-1170

\section{PRENATAL DIAGNOSIS OF DOWN SYNDROME IN ONE OF DIZYGOTIC TWINS}

K. Filkins, T. Kishnick, N. Diamond, et al.

Department of Obstetrics and Gynecology, Division of Human Genetics, New Jersey Medical School,

Newark

American Journal of Obstetrics and Gynecology (1978) 131:584-585

With the increasing employment of amniocentesis as a routine procedure for pregnant women over 35 years of age, the eventual finding of Down syndrome in one or both fetuses of a twin gestation could be anticipated. This report is probably the first involving antenatal diagnosis of Down syndrome in one of dizygotic twins.

$78-1-25$

EMOG-36-199

COMBINED TUBAL AND MULTIPLE INTRAUTERINE PREGNANCIES FOLLOWING OVULATION INDUCTION

N. Eckshtein, B. Ismajowich, G. Yedwab, and M.P. David

Department of Obstetrics and Gynecology, Municipal Government Medical Center, Hakirya Hospital, Tel

Aviv

Fertility and Sterility (1978) 30:707-709

An infertile woman who conceived after human menopausal gonadotropin-induced ovulation experienced ovarian hyperstimulation and a quintuplet gestation, an ectopic and a quadruplet intrauterine pregnancy. The intrauterine pregnancy was confirmed by B-scan ultrasonography about the time that the tubal pregnancy was ruptured. Salpingectomy did not interfere with the intrauterine pregnancy, but in spite of a cervical cerclage the patient developed premature labor after about $26 \mathrm{wk}$ of gestation.

78-1-26

EMOG-35-627

\section{THE RISKS OF TWIN PREGNANCY AND TWIN DELIVERY}

G.K. Doering, C.G. Hossfeld, and A. Auer

Geburtshilfe Gynakol. Abt. Stadt. Krankenh., München-Harlaching, Federal Republic of Germany

Geburtshilfe Frauenheilkunde (1978) 38:516-524

A statistical report is given on 200 twin pregnancies among a total of 20,665 births in 1966-1977. During pregnancy hyperemesis and toxemia were significantly more frequent than in an unselected control sample. The duration of pregnancy was strongly shortened (258 days versus 280.7 days). The frequency of pathological positions of the child was very high $(32.2 \%)$. Accordingly operative deliveries were very frequent $(55.7 \%)$. The incidence of caesarean section was high (20\%). In $32.2 \%$ of the twins the Apgar-Score was lower than 8 (versus $9 \%$ in the controls). The birth weight was on average $2244 \mathrm{~g}$ (versus $3385 \mathrm{~g}$ ). The frequency of premature birth was $57.2 \%$ (versus $5.4 \%$ ). The perinatal mortality of all twins was $19 \%$ (versus $1.5 \%$ ). The perinatal mortality of the children with a birth weight of lower than $2500 \mathrm{~g}$ was $14.4 \% .91 .5 \%$ of the twins who died perinatally were due to premature birth. The high perinatal mortality in twins is mostly a problem of prematurity. Comparing two samples with and without twin diagnosis in time gives the following results: Duration of pregnancy 263 versus 250.4 days; birth weight 2315 g versus 2107 g; perinatal mortality $4.5 \%$ versus $17.9 \%$. This shows the extreme importance of an early diagnosis of the twin pregnancy before birth. For the management of pregnancy and delivery there are recommendations given following the principle of prospective management of delivery used by us during the last 12 years. 
78-1-27

\section{OUTCOME OF PREGNANCY IN MOTHERS GIVEN BROMOCRIPTINE}

EME-40-1236

R.W. Griffith, I. Turkalj, and P. Braun

Biological and Medical Research, Sandoz LTD, Basel, Switzerland

British Journal of Clinical Pharmacology (1978) 5:227-231

Information has been obtained on the outcome of 448 completed pregnancies in mothers who had been given bromocriptine at some stage in the early weeks of pregnancy. The frequencies of spontaneous abortions, twin pregnancies and malformations have been compared with those reported for 'normal' populations. Based on this limited material, it is concluded that the use of bromocriptine to restore fertility in hyperprolactinaemic women is not associated with an increased risk of abortion, multiple pregnancy or the occurrence of malformations in the infants.

78-1-28

EME-40-845

\section{CORD SERUM PROLACTIN IN RELATION TO THE TIME OF THE DAY, THE SEX OF THE NEONATE AND THE BIRTH WEIGHT}

M. Badawi, C. Van Exter, J. Delogne-Desnoeck, et al.

Human Reproduction Research Unit, Université Libre Bruxelles, Hôpital Saint-Pierre, Brussels, Belgium Acta Endocrinologica (Copenhagen) (1978) 87:241-247

Serum prolactin was measured in 581 blood samples collected immediately after birth from 568 single newborn and from 9 pairs of twins. Cord serum prolactin is high at birth; the mean level is some 5 times higher than in adults. There is no sex difference in cord serum prolactin concentration in the neonate. Mean serum prolactin is significantly higher at 1.00 and $2.00 \mathrm{a} . \mathrm{m}$. Thus a circadian periodicity in serum prolactin concentration seems to appear already during foetal life well before the organization of sleep rhythm. Cord serum prolactin increases with birth weight ranging from $1500 \mathrm{~g}$ to $3500 \mathrm{~g}$. Thus, the control of levels of circulating prolactin changes during foetal life resulting in a progressive increase starting from mid-pregnancy. Mean cord serum prolactin at birth is lower in twins than in single newborns. There is no significant difference in serum prolactin between the first and second twin.

78-1-29

\section{EFFECTS OF DECREASED PRENATAL ACTIVITY IN PATIENTS WITH TWIN PREGNANCY}

H.R. Misenhimer and D.F. Kaltreider

Department of Obstetrics and Gynecology. Baltimore City Hospital

Obstetrics and Gynecology (1978) 51:692-694

In an attempt to reduce perinatal mortality in twin gestation, patients in whom the diagnosis was made prenatally were urged to remain in the hospital at reduced activity until the 36 th wk of pregnancy. 70 patients accepted this therapy during the yr 1964-1975. The perinatal mortality appeared to be reduced and a major benefit was noted in increased fetal weights.

78-1-30

EMPPS-40-2367

\section{TWINS: CAUSES OF PERINATAL DEATH IN 12 UNITED STATES CITIES AND ONE AFRICAN CITY}

R.L. Naeye, N. Tafari, D. Judge, and C.C. Marboe

Department of Pathology, M.S. Hershey Medical Center, Hershey, PA

American Journal of Obstetrics and Gynecology (1978) 131:267-272

The perinatal mortality rate in a large US study was 139 per 1,000 births for twins and 33 per 1,000 for singletons. $16 \%$ of the twin deaths were due to amniotic fluid infections, $11 \%$ to premature rupture of the membranes, $8 \%$ to the monovular twin transfusion syndrome, $8 \%$ to large placental infarcts, $7 \%$ to congenital anomalies, and the rest to over 20 other disorders. The perinatal mortality rate for monozygotic twins was 2.7 times that for dizygotic twins, mainly due to more amniotic fluid infections, congenital anomalies, and the twin transfusion syndrome in the monozygotic pairs. To study the role of poor maternal nutrition on twins, a similar study of perinatal mortality rates was undertaken in Addis Ababa, Ethiopia. Addis Ababa twins had 2.5 times the mortality rate of US twins, mainly due to a higher frequency of amniotic fluid infections, abruptio placentae, cord accidents, obstructed labors, congenital syphilis, and the twin transfusion syndrome in the Ethiopians. 
78-1-31

EMOG-36-635

\title{
SPONTANEOUS HYPERSTIMULATION OF THE OVARIES WITH LUTEAL CYSTS AND ASCITES DURING A TWIN PREGNANCY-EXTREME CASE OF THE SYNDROME OF PAINFUL EARLY PREGNANCY
}

\author{
D. Leis, K. Richter, and K. Schmid
}

II Frauenklin., University of Munich, Federal Republic of Germany

Geburtshilfe Frauenheilkunde (1978) 38:1085-1087

\begin{abstract}
Laparotomy was performed in a para II gravida II of 28 years in an early twin pregnancy. The left ovary was enlarged to $18 \times 8 \mathrm{~cm}$, the right ovary to $12 \times 8 \mathrm{~cm}$ by luteal cysts. The abdominal cavity contained an ample amount of peritoneal fluid. The history is understood as spontaneous ovarian hyperstimulation, and as an extreme case of the relatively common syndrome of painful early pregnancy, occasionally leading to unnecessary surgical intervention.
\end{abstract}

78-1-32

EMOG-36-932

\section{A REVIEW OF THE MANAGEMENT OF TWIN GESTATION}

\author{
G. Luck and C.I. Meeker
}

Obstetrics and Gynecology Department, Maine Medical Center, Portland

Journal of the Maine Medical Association (1978) 69:317-320

A review of the literature was conducted regarding the management of twin gestation. Both antepartum and intrapartum problems are discussed. The available data suggest that cesarean section should be used more liberally in twins, especially if the presentations are anything other than vertex/vertex.

78-1-33

EMOG-35-1777

\section{SIMULTANEOUS REGISTRATION OF FETAL HEART RATE IN TWIN PREGNANCIES}

K.H. Breuker, S. Kagel, and A. Bolte

University of Frauenklin.. Köln, Federal Republic of Germany

Geburtshilfe Frauenheilkunde (1978) 38:525-533

The results of continuous simultaneous registration of fetal heart rate in twin pregnancies are reported. The work was carried out with two identical cardiotocographs manufactured by Hewlett and Packard, which first registered the fetal heartbeats separately. An electronic control mechanism then transmitted the heart rate of the first twin to the control of the stylus of the second cardiotocograph, so that continuous double registration resulted. 75 prepartal and 15 intrapartal cardiotocograms were available for evaluation. During pregnancy, the combination of phono- and ultrasound-cardiotocography (66 cases) proved superior to phonocardiography alone (9 cases). Sub partu, the first twin was observed by means of direct fetal electrocardiography, the second twin by means of ultrasonocardiography. Separate registration of heart rate over a prolonged period could only be procured after the twenty-eighth week of pregnancy. $27.9 \%$ of the graphs were of excellent to satisfactory quality, $72 \%$ were unsatisfactory or not to be interpreted. Sub partu, $73.2 \%$ excellent to satisfactory results were obtained, and only $2.6 . \%$ were unsatisfactory. Compared to phonocardiographic observations on single pregnancies, the results during pregnancy were worse; during birth, however, they were just as good. The early stage of pregnancy, inconvenient position and heightened motility of the fetus were responsible for the large amount of inferior registration obtained in the prepartal observations. Sub partu, loss of quality in the external registrations on the second twin were due to movements by the mother and the elevation of the transducer from the maternal abdominal wall during labour. The problems of interpretation caused by loss of registration and non-instantaneous registration of the fetal heart rate are discussed. The significance of continuous and simultaneous CTG-registration of twins for early recognition of intrauterine fetal asphyxia is pointed out.

79-1-01

EMHG-23-2534

\section{ANTENATAL SEARCH FOR FETAL $\beta$ THALASSAEMIA IN A TWIN PREgNANCY}

H. Ward, M. Matsakis, M. Mouzouras, et al.

Department of Obstetrics and Gynaecology, University College Hospital Medical School, London British Journal of Obstetrics and Gynaecology (1979) 86:247-250

The antenatal search for fetal $\beta$ thalassaemia in a twin pregnancy is described. Thalassaemia major was correctly excluded in both fetuses, and some of the problems of identifying patients at risk are outlined as well as those of obtaining fetal blood in the second trimester of pregnancy. 
79-1-02

EMOG-36-2635

\section{ORAL CONTRACEPTION AND TWINNING: AN EPIDEMIOLOGIC STUDY}

M.B. Bracken

Department of Epidemiology and Public Health, New Haven, Connecticut

American Journal of Obstetrics and Gynecology (1979) 133:432-434

Among 4,428 women studied at five large hospitals in Connecticut, those conceiving within two months of cessation of oral contraceptive use had a twofold increased rate of delivering twins. This increase was found in both black and white women. Analysis of unlike and like sex twins indicates that this effect seems to clearly depend on an increased rate of dizygous twinning.

79-1-03

EMOG-36-2636

\section{THE USE OF ULTRASOUND IN MULTIPLE GESTATIONS}

W.A. Divers Jr. and D.L. Hemsell

Department of Obstetrics and Gynecology, Keesler USAF Medical Center, Keesler AFB, Biloxi, Mississippi Obstetrics and Gynecology (1979), 53:500-504

A retrospective study of 20 multiple pregnancies and a prospective study of 13 multiple pregnancies were done to determine the accuracy of ultrasound in the diagnosis and dating of multiple pregnancy and in predicting intrauterine growth retardation (IUGR). The diagnosis of 1 multiple pregnancy in our study was missed. In another case triplets were erroneously diagnosed as a twin gestation. Fetal biparietal diameter correlates well with gestational age, particularly when the characteristic growth pattern of twins is taken into account. Ultrasound was noted to be of only limited use in antenatal diagnosis of IUGR, with a significant number of false positives and false negatives noted.

79-1-04

EMPPS-41-2207

THE TWIN TRANSFUSION SYNDROME. CLINICAL OBSERVATIONS ON 35 AFFECTED PAIRS

K.L. Tan, R. Tan, S.H. Tan, and A.M. Tan

Department of Paediatrics, University of Singapore

Clinical Pediatrics (Philadelphia) (1979) 18:111-114

The twin transfusion or fetofetal transfusion syndrome is a relatively rare but interesting condition occurring in twins. It is one of the contributory factors to the increased morbidity and mortality in twin pregnancies. The weight difference between twin members presenting with this syndrome may be very marked in some instances, minimal in others. It has therefore been postulated that two types of this syndrome exist: a 'chronic' form existing during pregnancy, and an 'acute' form occurring only during parturition. The large numbers of deliveries occurring in the Kandang Kerbau Hospital, Singapore (about 25,000 annually) provided an opportunity for this condition to be studied, since a fair number of twins would be invariably delivered. It was therefore thought that an analysis of the data using the above concept might be worthwhile; the veracity of the concept could be assessed and perhaps its applicability extended. The present paper is an attempt at such a study.

79-1-05

EMOG-36-2078

\section{ON IMPROVED OUTCOME OF TWIN PREGNANCIES}

P.H. Persson, L. Grennert, G. Gennser, and S. Kullander

Department of Obstetrics and Gynecology, University of Lund, Sweden

Acta Obstetricia et Gynecologica Scandinavica (1979) 58:3-7

During the past $4 \mathrm{yr}$, an attempt has been made in Malmo to reduce the frequency of preterm termination of twin pregnancies. For this purpose, the entire pregnant population of this medium-sized city was subjected to general ultrasonic screening in the second trimester. This detected $88 \%$ of the twin pregnancies. The screening had a methodological error of $2 \%$. Eighty-six of the women with twin pregnancy were subjected to bedrest in hospital for more than $2 \mathrm{wk}$ in the second half of gestation. The incidences of twins born with birth weight below 1,500 $\mathrm{g}$ and of twins light-for-gestational-age were reduced compared with those a decade earlier. Also the group of twins born before the $37 \mathrm{th}$ wk decreased, and the perinatal mortality rate fell to the same level as in singleton pregnancies. Early detection of twin pregnancies followed by rest for the pregnant women seems to contribute to an improved outcome of these gestations. 
79-1-06

EMPPS-41-3078

\title{
DIAGNOSIS OF POOR INTRAUTERINE FETAL GROWTH IN TWIN PREGNANCIES
}

\author{
J. Klammer, A. Bichler, W. Brabee, and O. Dapunt \\ Univ. Klin. Frauenheilk., Innsbruck, Austria \\ Zeitschrift für Geburtshilfe und Perinatologie (1979) 183:12-18
}

30 twin pregnancies were studied with regard to intrauterine growth retardation. In 11 cases both twins were of normal weight. In 7 cases one twin and in 12 cases both twins were under-weight (the growth retardation was classified according to the intrauterine growth curves after Hohenauer, applicable to our area). The determination of total 24 hour urinary estrogens and serial ultrasonic measurements of biparietal diameters appeared to be the best parameters for the detection of intrauterine growth retardation. Serum HPL determination was unreliable. In addition 2 types of growth retardation in twins could be recognized from the estrogen values. In one, a dysfunction of the fetoplacental unit existed; in the other, the etiology of the growth retardation could not be determined by the methods used in the study (genetic origin?).

\section{TWIN DEVELOPMENT AND TWIN RESEARCH IN DEVELOPMENTAL STUDIES}

78-2-09

EMHG-22-2183

\section{PROFILE COMPARISONS OF PHYSICAL GROWTH FOR MONOZYGOTIC AND DIZYGOTIC TWIN PAIRS}

\author{
S. Fischbein and T. Nordquist \\ Department of Educational Research, Stockholm Institute of Education, Sweden \\ Annals of Human Biology (1978) 5:321-328
}

\begin{abstract}
Three different methods of analysing similarity of physical growth curves within $\mathrm{MZ}$ and $\mathrm{DZ}$ twin pairs are compared. The concordance of the curves for each pair can be measured by either a multiple regression coefficient $\left(R^{2}\right)$ or the square root of the sum of squared differences between corresponding deviation points (D). The latter seems to be a more appropriate measure of profile contour similarity, mainly because the distance between curves is allowed for. An intra-class correlation based on a longitudinal analysis of variance seems to be a useful measure of average profile similarity for comparing groups of individuals. The distributions of the $D$ measures, calculated for all MZ and DZ twin pairs, show MZ pairs to have significantly smaller D-values for both height and weight, on average, than DZ pairs. The intra-class correlations also show a higher concordance in developmental profile for $\mathrm{MZ}$ in comparison to $\mathrm{DZ}$.
\end{abstract}

\section{TWIN RESEARCH IN COGNITIVE STUDIES}

78-3-05

EMPPS-40-2344

\section{THE EFFECTS OF CHORION TYPE ON VARIATION IN IQ IN THE NCPP TWIN POPULATION}

M. Melnick, N.C. Myrianthopoulos, and J.C. Christian

Developmental Neurology Branch, National Institute of Neurological Communicative Disorders Stroke, NIH, Bethesda, Maryland

American Journal of Human Genetics (1978) 30:425-433

The 7-year IQ scores (WISC) of 116 white and 143 black nonmalformed twins of known azygosity and placental type were ascertained from the NINCDS Collaborative Perinatal Project (NCPP). The type of chorion and zygosity had no significant effect on the mean IQ or among-pair variation. In white monozygotic twins, however, analysis of variance revealed a significantly greater within-pair mean square for dichorionic twins than monochorionic twins. On the other hand, the white dichorionic monozygotic (MZ) and dizygotic (DZ) within-pair mean squares were quite similar. These findings were not evident in blacks for either of the within-pair comparisons. In addition, estimates of genetic variance were dependent upon $\mathrm{MZ}$ chorion type in both races. These data suggest to us that in white twin pairs dichorionic placentas are of greater influence than the similarity 
or dissimilarity of genomes with regard to intrapair IQ development, and failure to consider chorion type may introduce a serious bias in the interpretation of genetic variance estimates of IQ variability.

78-3-06

\title{
CRITICISM OF THE TWINS METHOD FOR MENTAL TESTS' HEREDITY
}

EMHG-23-107

\author{
G. Olivier
}

Laboratory of Anthropology and Biology, University of Paris

Bulletin et Mémoires de la Société d'Anthropologie (Paris) (1978) 13V:143-148

The study of heredity of intelligence has two great difficulties: the development of intelligence requires an apprenticeship, not separable from the environment; heredity is both genetic and social; the twin method is inadequate, because it wrongly presupposes an identical milieu; between monozygotic and dizygotic twins the milieu is different, because of the low birth weight and the formation of the twin couple, which frequently involve mental retardation.

\section{TWIN RESEARCH IN PERSONALITY, PSYCHOPHYSIOLOGY, AND PSYCHOPATHOLOGY}

77-4-07

EMHG-23-413

\section{AN APPLICATION OF THE ANALYSIS OF COVARIANCE STRUCTURES TO THE PSYCHOGENETICAL STUDY OF IMPULSIVENESS}

\author{
L.J. Eaves, N.G. Martin, and S.B.G. Eysenck \\ Department of Genetics, University of Birmingham, Great Britain \\ British Journal of Mathematical and Statistical Psychology (1977) 30:185-197
}

\begin{abstract}
A method based on Joreskog's approach to the analysis of covariance structures is applied to the genotypeenvironment analysis of the covariation of four aspects of impulsiveness in male and female monozygotic and dizygotic twins. The data are consistent with a simple model which assumes additive gene action, random mating and environmental effects within families. Further, it is shown that genotypic factor loadings can be regarded as constant multiples of corresponding environmental loadings. Trait-specific sex interactions are detected which suggest that some mechanism of sex-limitation could contribute to specific variation.
\end{abstract}

78-4-19

EMHG-23-1077

\section{GENETIC APPROACHES TO THE STUDY OF SCHIZOPHRENIA: THE GENETIC EVIDENCE AS A TOOL IN RESEARCH}

\section{Erlenmeyer-Kimling}

Department of Psychiatry, Columbia University, New York

Birth Defects Original Article Series (1978) 14:59-74

At least 20 points of evidence can currently be said to provide the support for the hypothesis of hereditary involvement in schizophrenia. Many of these same lines of evidence also make clear the fact that an important environmental influence must be taken into account. From historic accounts which describe schizophrenia-like behavior in societies of the remote past and from epidemiologic data and clinical reports which establish the existence of schizophrenia in a wide range of present-day societies-primitive, pastoral, and technologic-it is clear that this disorder, or group of disorders, has not been confined to any one type of culture or social setting. This does not imply, of course, that the frequency of schizophrenia or of schizophrenic genes has been the same at all times and places. It follows from the foregoing point that we might not expect to find a specific environmental agent or event which is invariably associated with schizophrenia, and, in fact, no such agent or event has ever been found. 


\title{
5. TWIN RESEARCH IN SUBSTANCE EXPOSURE AND COTWIN CONTROL STUDIES
}

77-5-01

EMHG-22-179

\section{THE INTERACTIONS OF SMOKING, ENVIRONMENT AND HEREDITY AND THEIR IMPLICATIONS FOR DISEASE ETIOLOGY}

\author{
R. Cederlof, L. Friberg, and T. Lundman
}

Department of Environmental Hygiene, Karolinska Institute, Stockholm, Sweden

Acta Medica Scandinavica (1977) 202(suppl 612):128

\begin{abstract}
The presentation of the twin research program in this report has so far involved an extensive description of methodological aspects of the twin method as well as a detailed account of various results from a series of questionnaire studies, clinical examinations, and mortality follow-ups. Upon the initiation of the twin program two major assumptions were made. The first was that smokers differ from nonsmokers in many aspects relevant for developing disease and for increasing the risk of premature death. The second assumption was that many such variables would be more similar between the two members of a twin-pair as compared to unrelated individuals even if the twins in a pair were dissimilar in regard to smoking. The most dramatic association was shown in regard to drinking and especially excessive drinking. Consumers of more than 16 cigarettes a day drank excessive amounts of alcohol 3-10 times more often than the nonsmokers. Sleeping pills and tranquillizers were used 3-5 times as often among the high cigarette smokers as among the nonsmokers. The use of oral contraceptives among women was strongly related to amount of smoking. Indications of psycho-social discord were also related to smoking. Sleeping difficulties and stress were thus reported about twice as often by the smokers in the highest cigarette smoking category as compared to nonsmokers. Divorce was about four times as common among high smokers as among nonsmokers. A personality measurement according to a special psycho-social scale showed that instability was up to three times more common among the high smokers, and extravertness appeared to be moderately but significantly more common in the smoking groups as compared to nonsmokers. In regard to several traits, the prevalence rate among nonsmokers in the discordant group proved to be significantly increased in comparison to all nonsmokers in the twin series. These findings-whether genetically or environmentally determined - motivate an assumption of a lifestyle parameter that expresses itself in the development of not only smoking behavior but also of a great variety of habitual traits. Smoking could then be regarded as one of many indices of this parameter. Cause specific mortality ratios are found to be significantly increased for coronary heart disease, lung cancer, suicides and accidents in several subgroups. The results from the twin study clearly demonstrate the importance of genetic, several behavioral and psychosocial factors which have not been considered in conventional epidemiological studies. Such factors should as far as possible be included in future epidemiological research, not only in the context of smoking and health, but also in studies on other similar exposure factors that may be linked to risk factors of this type or to genetic predispositions. The twin approach certainly enhances the group comparability to a considerable extent not only in regard to genetic but also with respect to habitual and psychosocial factors that may be of etiologic relevance. The major drawback of the twin method is the question of numbers, a difficulty, however, that can be resolved by integrating data from several research centers using the twin method. Such programs are under way.
\end{abstract}

78-5-05

\section{TWIN STUDIES IN PHARMACOGENETICS}

EMHG-22-2748

E.S. Vesell

Department of Pharmacology, Pennsylvania State University College of Medicine, Hershey

Human Genetics (1978) 45(suppl1):19-30

Twin studies can serve for several distinct purposes as useful first steps in pharmacogenetic analysis. They may be employed as an initial screen to determine whether genetic factors play a major role in producing phenotypic variation in drug disposition. If genetic factors are operative, high concordance rates among $D Z$ twins suggest control by alleles at a single genetic locus. Then the results of these initial screening studies on twins can also serve to identify those individuals in whom family studies would be particularly enlightening. In utilizing the twin, or any other pharmacogenetic technique, care should be taken in the analysis to come as close as possible 
to the gene product. This means isolating the particular enzyme or protein causing the phenotypic variation, as in our recent twin studies on drug binding to isolated, purified albumins (Wilding et al., 1978). However, this practice is rarely feasible in pharmacogenetic studies on human beings. Genetic interpretations may be very ambiguous if only disappearance of a parent drug is measured, especially if the parent drug is subjected to several distinct catabolic reactions. Clearly, measurement of individual metabolites is preferable, as in our twin studies on trichloroacetic acid concentrations in urine after $\left[{ }^{14} \mathrm{C}\right]$ halothane administration (Cascorbi et al., 1971). Nevertheless, caution ought to be exercised in taking urinary measurements of relatively unstable hydroxylated metabolites as precise reflections of the amount of metabolite released at the site of hepatic biotransformation. Many opportunities exist for both loss of an addition to these metabolites between their production by liver enzymes and their appearance in urine. It would be unfortunate to ignore the opportunities offered by twin studies in future pharmacogenetic endeavors because twin studies cannot provide final, definitive conclusions with respect to identifying precise modes of genetic transmission. Rather, it would seem wiser to retain the twin method as an initial approach in a kind of tier system, analogous to the currently employed tier testing of potentially mutagenic agents. Thus, the advantages of the twin method could be utilized to provide rapidly the information necessary before taking the next step in the tier: family studies.

\title{
6. TWIN RESEARCH IN PHYSIOLOGY AND ANTHROPOLOGY
}

77-6-03

EMHG-23-164

\section{GENETIC CONTROL OF INTERINDIVIDUAL VARIATIONS IN RACEMIC WARFARIN BINDING TO PLASMA AND ALBUMIN OF TWINS}

\author{
G. Wilding, B. Paigen, and E.S. Vesell \\ Department of Pharmacology, Pennsylvania State University College of Medicine, Hershey \\ Clinical Pharmacology and Therapeutics (1977) 22:831-842
}

Warfarin binding to plasma as well as to charcoal-treated purified albumin was studied in monozygotic (MZ) and dizygotic (DZ) twins by equilibrium dialysis. The association constants of warfarin binding and the number of warfarin binding sites per molecule were more similar within MZ than within DZ twins. These data indicate that genetic factors control interindividual variations in warfarin-albumin association constants and in the number of warfarin binding sites per albumin molecule. A heritability index of 0.87 was obtained for the association constant of warfarin binding to plasma and of 0.89 for warfarin binding to albumin. Heritability indices of 0.80 and 0.85 were obtained for the number of warfarin sites per albumin molecule in plasma and albumin, respectively. When the values of $\mathrm{Ka}$ and $\mathrm{n}$ for warfarin binding to albumin are plotted for the 44 individuals in this study, the distribution of $\mathrm{Ka}$ as well as $\mathrm{n}$ appears to be trimodal. The distribution of $\mathrm{n}$ falls into three classes, with 19 having an average binding site of $0.9,14$ having an average binding site of 1.4 and 3 having an average binding site of 2.1. Since this distribution conforms to a Hardy-Weinberg equilibrium with gene frequencies of 0.72 and 0.28 and since the average number of binding sites is close to integral numbers of 1 and 2 , it is tempting to speculate that these data disclose for the first time a common polymorphism of the albumin molecule affecting both $\mathrm{n}$ and $\mathrm{Ka}$ such that the phenotypic variations are controlled by two alleles at a single genetic locus. Since the number of subjects is too small for this distribution analysis to be completely secure, family studies will be required to determine whether such a polymorphism exists. Ka and $\mathrm{n}$, though significantly correlated, have $r$ values that are not very high (for isolated albumin, $r=0.63$ for Ka vs $n$ in $\mathrm{MZ}$ twins, $\mathrm{p}<0.01 ; \mathrm{r}=0.34$ for $\mathrm{Ka}$ vs $\mathrm{n}$ in $\mathrm{DZ}$ twins, $\mathrm{p}=0.05$; for whole plasma, $\mathrm{r}$ equals 0.78 for $\mathrm{n}$ vs $\mathrm{Ka}$ in $\mathrm{MZ}$ twins, $p<0.01 ; r=0.57$ for $n$ vs $\mathrm{Ka}$ in $\mathrm{DZ}$ twins, $p<0.01$ ). With respect to avidity of warfarin binding and number of warfarin sites per albumin molecule, these results suggest that inherited structural differences in the albumin molecule may affect the transport of certain drugs within the body of normal subjects. Presence in plasma of endogenous ligands that bind tightly to albumin, such as bilirubin and fatty acids, which fluctuate with environmental variables such as diet, apparently do not exert as great an effect as had been anticipated in concealing this genetic control over drug binding. Closely similar heritability indices obtained for the binding parameters in untreated plasma and in purified charcoal-treated albumin suggest that the differential binding of ligands may not be responsible for the variability observed and that the genetic control of this variability may be expressed less on the nature of the ligands and their binding than on the structure of the albumin molecule. 
GENETICAL DISTANCE AND DERMATOGLYPHIC CHARACTERS. III. DERMATOGLYPHIC DISTANCES WITHIN TWIN PAIRS, BETWEEN LEFT AND RIGHT SIDES AND BETWEEN NORMALS AND 21-TRISOMICS

\author{
D. Loesch, H. Lisiewicz, and J. Czyzewska \\ Department of Human Genetics, Psychoneurological Institute, Warsaw, Poland \\ Human Heredity (1978) 28:456-467
}

The dermatoglyphic (genetical) distance coefficients have been estimated within monozygotic and dizygotic twin pairs, between left and right sides of the same individual and between normal subjects and 21-trisomics. All the coefficients have been based, in turn, on frequencies of fingertip, palmar and sole pattern elements, separately and for all characters combined. Quantitative variables (pattern intensities) have also been used for independent evaluation of the $(\mathrm{C}(\mathrm{H}))^{2}$ distance coefficient in monozygotic and dizygotic twins, and in 21 trisomics as compared with normal individuals. The values of a distance have then been considered in relation to the degree of genetical likeness between the compared items as well as to the relative contribution of each pattern combination to the overall value of a distance. Some limitations in the interpretation of the results, connected mainly with statistical procedures, are also discussed.

78-6-05

EMHG-22-746

\title{
COMPARISONS OF DERMATOGLYPHIC PATTERNS IN MONOCHORIONIC AND DICHORIONIC MONOZYGOTIC TWINS
}

T. Reed, I.A. Uchida, J.A. Norton Jr., and J.C. Christian

Department of Medical Genetics, Indiana University School of Medicine, Indianapolis

American Journal of Human Genetics (1978) 30:383-391

The data presented here indicate that different influences affect dermatoglyphic pattern development in MC$\mathrm{MZ}$ and DC-MZ twins. Only five of 84 variables had significant mean differences but their clustering suggested a real difference in mean placement of the atd angle. Nineteen of 84 variables had significantly different withinpair mean squares for the two twin types. Larger numbers of twins will be required to obtain accurate estimates of the magnitude of the dermatoglyphic differences between MC-MZ and DC-MZ twins. Studies of dermatoglyphics in MC-MZ and DC-MZ twins are important to the understanding of factors which influence early embryonic development and when better documented may provide a mechanism for retrospectively diagnosing placental type of $\mathrm{MZ}$ twins.

78-6-06

EMHG-23-408

\section{DERMATOGLYPHIC TOTAL PATTERNS ON PALMS, FINGER-TIPS AND SOLES IN TWINS}

D. Loesch and Z. Swiatkowska

Department of Genetics, Psychoneurology Institute, Warsaw, Poland

Annals of Human Biology (1978) 5:409-419

110 palms of $\mathrm{MZ}$ twins and 111 like-sexed pairs of DZ twins have been compared in respect of a concordance rate of the palmar, sole and finger-tip total pattern types. Dermatoglyphic patterns have been classified according to the topological method, and the distributions of the numbers of discordant pattern elements from homolateral, heterolateral and bilateral comparisons in MZ and DZ twins, respectively, are presented. The highest concordance occurs in homolateral comparisons. Bilateral concordance is highest for sole and finger-tip patterns, while palmar patterns present a considerable degree of dermatoglyphic asymmetry. Palmar, sole and finger-tip patterns are also not alike in homolateral concordance rates with $\mathrm{MZ}$ and $\mathrm{DZ}$ twin pairs. The differences between $\mathrm{MZ}$ and DZ twins are much more pronounced for sole patterns than for palmar or finger-tip patterns, which is also reflected in the estimated $\mathrm{H}$ values. For soles, this may be in some way related to the considerable symmetry of patterns. The fact that some pattern elements are intercorrelated may also introduce a bias in estimates of heritability, based on twin material. 


\title{
SIGNIFICANCE OF BIPARIETAL DIAMETER DIFFERENCES BETWEEN TWINS
}

\author{
A.F. Haney, M.C. Crenshaw Jr., and P.J. Dempsey \\ Department of Obstetrics and Gynecology, Division of Perinatal Medicine, Duke University Medical Center, \\ Durham, North Carolina \\ Obstetrics and Gynecology (1978) 51:609-613
}

\begin{abstract}
Twins of dissimilar size have increased risks both at delivery and in the neonatal period. When dissimilar growth is severe, it should be reflected in birthweight and biparietal diameter (BPD) growth. Sonograms were done on 74 of 106 sets of twins delivered from July 1, 1973, to June 3, 1974. Excluding prematurity and birth trauma, the difference in BPD between twins with normal outcomes in the last scan prior to delivery was $1.32 \pm 0.20 \mathrm{~mm}$ (mean $\pm \mathrm{SE}$ ) and the difference in birthweight was $250.3 \pm 31.4 \mathrm{~g}$ (mean $\pm \mathrm{SE}$ ). In 7 sets of twins with poor outcomes (intrauterine fetal demise or severe intrauterine growth retardation) without central nervous system anomalies, the difference in BPD between twins in the last scan, while both fetuses were alive, was $6.86 \pm 1.06 \mathrm{~mm}$ (mean $\pm \mathrm{SE}$ ) and the difference in birthweight was $604.3 \pm 217.2 \mathrm{~g}$ (mean $\pm \mathrm{SE}$ ). Both the BPDs and birthweights were significantly different at the $\mathrm{P}<0.01$ level. Large differences in BPD between twins may possibly indicate compromise of one twin.
\end{abstract}

78-6-08

EMHG-23-1545

\section{ARYL HYDROCARBON HYDROXYLASE IN CULTURED LYMPHOCYTES OF TWINS}

B. Paigen, E. Ward, K. Steenland, et al.

Department of Molecular Biology, Roswell Park Memorial Institute, Buffalo

American Journal of Human Genetics (1978) 30:561-571

Measurement of aryl hydrocarbon hydroxylase $(\mathrm{AHH})$ in cultured lymphocytes of 18 monozygotic and 30 dizygotic twin pairs showed that basal and induced $\mathrm{AHH}$ activity and $\mathrm{AHH}$ inducibility are heritable traits. The data are consistent with $\mathrm{AHH}$ inducibility being determined by a single or a very few polymorphic genes.

78-6-09

EME-40-919

\section{PLASMA CORTISOL LEVEL IN MONOZYGOTIC AND DIZYGOTIC TWINS}

B. Raczynska, J. Lukaszewska, and M. Sklad

Zakl. Biol. Institute Nauk Biomed., Akademie Wychowania Fiz., Warsaw, Poland

Endokrynologia Polska (1978) 29:7-10.

The heritability of plasma cortisol level was investigated in men. The twin method, consisting of the comparison of monozygotic (MZ) and dizygotic (DZ) pairs of twins was employed. The cortisol level in 94 pairs of twins ( $50 \mathrm{MZ}$ and $44 \mathrm{DZ}$ ) of both sexes, from 8 to 15 years, was determined by the modified method of Murphy. The results suggest that the cortisol secretion in men is more similar in the individuals of identical genotypes in comparison to those having different genotypes.

78-6-10

\section{HEREDITARY ASPECTS OF DECREASED HYPOXIC RESPONSE}

EMHG-22-2172

D.D. Collins, C.H. Scoggin, C.W. Zwillich, and J.V. Weil

Cardiovascular and Pulmonary Research Laboratory, University of Colorado Medical Center, Denver

Journal of Clinical Investigation (1978) 62:105-110

Decreased ventilatory responses to hypoxia and hypercapnia have been demonstrated in a variety of disorders: however, the etiology of these decreased drives remains virtually unknown. Recent observations have suggested a familial influence on hypoxic and hypercapnic ventilatory response, but it is unclear whether this influence is the result of hereditary or environmental influences. Therefore we measured the ventilatory response to isocapnic hypoxia (HVR) and hyperoxic hypercapnia in 12 pairs of identical and 12 pairs of nonidentical twins. Significant correlation $(P<0.01)$ was found for HVR within identical twin pairs but not within nonidentical twin pairs. Identical twins resembled each other more closely with respect to HVR than was the case for nonidentical twins $(\mathrm{P}<0.0125)$. This was independent of body size, blood $\mathrm{PCO}_{2}$, or $\mathrm{pH}$. No such correlation could be found for ventilatory response to hyperoxic hypercapnia. It is concluded that hereditary influences affect HVR and it is speculated that such influences may play a role in clinical conditions characterized by decreased hypoxic ventilatory responses. 


\title{
IDENTICAL TWINS WITH DIFFERING FORMS OF VENTRICULAR PRE-EXCITATION
}

\author{
D.H. Bennett, B. Gribbin, and J.S. Birkhead \\ Cardiology Department, Radcliffe Infirmary, Oxford, Great Britain \\ British Heart Journal (1978) 40:147-152
}

\begin{abstract}
Identical 10-year-old twins, both with electrocardiograms showing a short PR interval and a normal QRS complex but with dramatically different electrophysiological characteristics, are described. One twin experienced episodes of rapid palpitation and on one occasion was resuscitated from ventricular fibrillation. An intracardiac electrophysiological study confirmed the presence of an atrioventricular nodal bypass tract and in addition revealed the presence of an accessory atrioventricular pathway, thus demonstrating that the patient had both the Lown-Ganong-Levine and Wolff-Parkinson-White syndrome. Re-entry tachycardia and atrial fibrillation, with a very rapid ventricular rate, were precipitated. After treatment with amiodarone, the patient became asymptomatic and a repeat study showed that the features of the atrioventricular nodal bypass tract were no longer present and though re-entry tachycardias using the accessory atrioventricular pathway could still be induced, their rates were slower than before treatment. The other twin, in spite of an identical surface electrocardiogram, was asymptomatic. An electrophysiological study showed the features of an atrioventricular bypass tract but there was no evidence of additional atrioventicular accessory connections and a tachycardia could not be induced.
\end{abstract}

78-6-12

EMPH-45-3403

\section{EFFECT OF ISOMETRIC STRENGTH TRAINING ON MECHANICAL, ELECTRICAL, AND METABOLIC ASPECTS OF MUSCLE FUNCTION}

P.V. Komi, J.T. Viitasalo, R. Rauramaa, and V. Vihko

Kinesiologic Laboratory. Department of Biology and Physical Activity, University of Jyvaskyla, Finland European Journal of Applied Physiology and Occupational Physiology (1978) 40:45-55

Monozygous twin pairs (two female and four male) were used in a strength training study so that one member of each pair served as training subject (TS) and the other members as nonexercising controls (CS). TS trained four times a week for 12 weeks with maximal isometric knee extensions of the right leg. The parameters studied included muscle strength, endurance time, electromyographic activity, and activities of several key enzymes in nonoxidative and oxidative muscle metabolism. The results disclosed that in addition to a $20 \%$ increase in isometric knee extension strength in the trained leg of TS, an average increase of $11 \%$ was observed in strength of TS untrained leg. CS did not demonstrate any change in muscle strength. Training also included an improvement in the maintenance of a static load of $60 \%$ of the pretraining maximum. Increase in the maximum integrated electromyographic activity (IEMG) of the rectus femoris muscle occurred concomitantly with the knee extension strength. Training also caused reduction in the IEMG/tension ratio at submaximal loads indicating a more economical usage of the rectus femoris muscle. Muscle biopsies taken from the vastus lateralis muscle showed that the enzyme activites of MDH, SDH, and $\mathrm{HK}$ were higher, and $\mathrm{LDH}$ and CPK lower in the trained leg as compared to the nontrained control leg of TS or to the values of the untrained member of the twin pair. It is concluded that isometric strength training as used in the present study can cause increased recruitment of the available motor unit pool, improved efficiency at submaximal loads, and surprisingly also enhancement of the oxidative metabolism in the muscle.

78-6-13

STUDIES ON THE CHANGES OF SERUM FSH, LH AND PROLACTIN CONCENTRATIONS IN PUBERTAL TWINS

EMPPS-41-2511

T. Wasada, Y. Akamine, H. Oma, et al.

III Department of Internal Medicine, Faculty of Medicine, Kyushu University, Fukuoka, Japan

Endocrinologia Japonica (1978) 25:575-582

A cross-sectional study was undertaken to investigate the correlation of serum gonadotropin levels with physical signs of puberty and also to assess the role of genetic factors in the onset and progression of puberty. Serum concentrations of FSH, LH and prolactin were measured by double antibody radioimmunoassay in 195 monozygotic and 59 dizygotic twin pairs during the years of puberty (12 to 15 years). In boys serum FSH, LH and prolactin concentrations showed a tendency to increase steadily along with bone ages (9 to 17 years). The size of testis correlated fairly well with serum LH levels and to some extent with FSH. In the pubic hair stage, a 
significant difference was observed in serum FSH and LH levels between the groups of PH 1-2 and PH $3<$. In girls, serum FSH levels significantly increased in the early phase of puberty and no further increase occurred thereafter, while serum LH and prolactin levels showed an increasing trend with the advance of bone ages to adult levels. As to breast development, serum LH levels alone increased during the early stages of development. When a comparison was made between pre- and post-menarchial groups or between pubic hair stages, a significant difference was present only in LH levels in either comparison. From a viewpoint of twin zygosity, the intrapair differences of serum gonadotropin levels were compared between monozygotic and dizygotic pairs of twins. Serum LH levels in both sexes and serum FSH in girls of monozygotic pairs of twins showed a significant within-pair similarity compared with dizygotic pairs of twins. Since serum LH levels appeared to have a close relationship with the advancement of puberty in both sexes, these findings suggest that genetic factors play an important role in the onset and progression of individual puberty.

79-6-01

EMHG-23-1808

\section{ANALYSIS OF FAMILY RESEMBLANCE FOR LIPIDS AND LIPOPROTEINS}

L. Iselius

Population Genetics Laboratory, University of Hawaii, Honolulu

Clinical Genetics (1979) 15:300-306

A path analysis of published reports of family resemblance reveals an important role for genetic factors in all lipids and lipoproteins, with no evidence of a discrepancy between twins and other relatives (which might be due to dominance or epistasis) nor between studies which used environmental indices and those which did not. Family environment within population is less important and is significantly greater for twins than for other relatives.

\section{TWIN RESEARCH IN CLINICAL STUDIES}

77-7-01

EMHG-22-1976

\section{TWO MONOZYGOTIC TWIN SISTERS AFFECTED WITH A SEVERE FORM OF OSTEOGENESIS IMPERFECTA CONGENITA}

J.N. Le Freche, C. Le Gouguec, and B. Le Marec

Consultations Genetiques, Service Pediatrique, Central Hospital of the University of Pontchaillou, Rennes, France

Journal de Genetique Humaine (1977) 25:291-294

Description of two monozygotic twin sisters both showing a severe form of osteogenesis imperfecta.

77-7-02

EMO-33-112

\section{UNUSUAL DEVELOPMENTAL ANOMALY OF THE MACULA, CHARACTERIZED BY BILATERAL 'PAPILLOMACULAR RETINAL FOLD' IN IDENTICAL TWINS}

Y. Shiose, T. Kanda, T. Itoh, and Y. Kawase

Division of Ophthalmology, Aichi Pref. Center Health Care, Nagoya, Japan

Japanese Journal of Ophthalmology (1977) 21:507-515

Monozygous male twins, aged $20 \mathrm{yr}$, presented bilateral microphthalmos and high hyperopia of +14.0 diopters with the best corrected vision of less than 0.4 . While the cornea was of normal size, the ocular axial length measured about $17 \mathrm{~mm}$. The most characteristic finding was a wing-shaped retinal elevation extending from the macula toward the optic disc analogous to the papillomacular retinal fold as described by Uemura and Boynton. Fluorescein angiography revealed the absence of the avascular area in the fovea. It appears that this peculiar condition was caused by an arrested development of the outer ocular coat during the late fetal life resulting in a heap of exuberant inner neural retina in the papillomacular region. An autosomal recessive inheritance is suspected, on the basis of occasional occurrence in sibship and parental consanguinity. 


\title{
THE BRONZE-BABY-SYNDROME: A COMPLICATION OF PHOTOTHERAPY
}

\author{
E.H. Radermacher, A. Noirfalise, H. Hoernchen, et al.
}

Abt. Kinderheilk. RWTH, Aachen, Federal Republic of Germany

Klinische Paediatrie (1977) 189:379-384

\begin{abstract}
A case of intense-brown discoloration of the skin, serum and urine in a premature twin is reported when phototherapy was used to reduce hyperbilirubinemia. All features made the diagnosis of bronze-baby-syndrome most probable. The authors were able to detect an increased level of coproporphyrin in the serum. The patient did not show any signs of a kernicterus. Possible speculations about the pathogenetic and prognostic value of elevated levels of coproporphyrins in newborn infants under treatment with phototherapy are discussed. In these cases one must be aware of possible neurotoxic effects, since increased concentrations of bilirubin breakdown products may not be excreted as well through the normal biliary passage as normally.
\end{abstract}

77-7-04

EMHG-22-2253

\section{CONGENITAL FIBER TYPE DISPROPORTION IN IDENTICAL TWINS}

R.G. Curless and M.B. Nelson

Department of Pediatrics, University of Arizona College of Medicine, Tucson

Annals of Neurology (1977) 2:455-459

Eighteen-month-old identical twins with the muscle histological characteristics of congenital fiber type disproportion are reported. The fiber typing system of $\mathrm{pH}$-dependent adenosine triphosphatase was used to analyze the size and percentage of type 1, 2A and 2B fibers in muscle tissue obtained by needle biopsy. Both twins had significantly larger type 2 than type 1 fibers, with $2 \mathrm{~B}$ fibers representing the largest type. One patient also had type 1 predominance at the expense of a reduction in $2 \mathrm{~B}$ ( $2 \mathrm{~B}$ deficiency). The probands as well as other family members had transient delayed motor development, macrocephaly, and normal intelligence. A biopsy obtained from 1 of these family members failed to demonstrate a similar histological abnormality. The disorder is nonprogressive in this family, as evidenced by minimal disability in the older members and gradual improvement in the probands.

78-7-01

EMPPS-40-2103

\section{PERSISTENT MULLERIAN DUCT SYNDROME IN MALE IDENTICAL TWINS}

E.B. Weiss, J.H. Kiefer, U.F. Rowlatt, and I.M. Rosenthal

Department of Pediatrics, Abraham Lincoln School of Medicine, University of Illinois, Chicago

Pediatrics (1978) 61:797-800

Male pseudohermaphroditism, characterized by the persistence of Mullerian duct structures with otherwise normal differentiation, is a rare disorder that appears to be caused by an abnormality in the activity of Mullerian inhibiting factor. Patients with this syndrome are phenotypically normal males who usually present with inguinal hernia and cryptorchidism. This condition has also been called hernia uteri inguinalis, persistent Mullerian duct syndrome, and male internal pseudohermaphroditism. It has recently been suggested that hysterectomy may not be indicated in most of these patients because of possible injury to the vas deferens. The condition appears to be genetic, since familial incidence occurs. The occurrence of this condition in male identical twins is reported.

78-7-02

EMHG-23-268

\section{PERSISTENT CLOACA WITH ABSENT PENIS AND ANAL ATRESIA IN ONE OF IDENTICAL TWINS}

H. Koffler, J.M. Aase, L.A. Papile, and R.W. Coen

Department of Pediatrics, University of New Mexico School of Medicine, Albuquerque

Journal of Pediatrics (1978) 93:821-823

Persistence of the primitive cloaca with absence of the urethra, absence of the external genitalia, and anal atresia is described in one sibling of a monoamniotic-monochorionic twin birth. The infant also had severe bilateral renal dysplasia but no evidence of pulmonary hypoplasia. 
78-7-03

EMCD-30-2845

\section{MYXOMA OF THE RIGHT VENTRICLE IN MONOZYGOTIC TWINS. SURGICAL REMOVAL}

L. Laboux, J. Mussini-Montpellier, J.L. Michaud, et al.

Clinique Chir. Thorac. Cardiovasculaire, Hôpital Loennec, Nantes, France

Archives des Maladies du Coeur et des Vaisseaux (1978) 71:953-959

Monozygotic twins aged 23 underwent surgery, at an interval of 4 months from each other, for a myxomatous tumour of the right ventricle which had been completely asymptomatic until then. The authors present the clinical, electrocardiographic and angiographic findings, together with details of the operation and of the histological findings. They recall how rare a site this is, and summarise some of the observations which have been made on familial myxomas.

78-7-04

EMCD-30-1775

\section{TAKAYASU'S DISEASE IN TWIN SISTERS. POSSIBLE GENETIC FACTORS}

F. Numano, I. Isohisa, U. Kishi, et al.

Department of Internal Medicine, Tokyo Medical and Dental University School of Medicine, Yushima, Japan

Circulation (1978) 58:173-177

Takayasu's disease is well-known for its characteristic clinical features and its elusive etiology. Recently, we encountered twin Japanese sisters, both of whom were diagnosed as having Takayasu's disease. The parents, two sisters, and one brother are healthy. Family history revealed the parents are first cousins. Analyses of several blood types and HLA typing were performed on all members of the family, and it was confirmed that these twins are monozygotic. Moreover, HLA typing analyses revealed that one haplotype found in the father was passed only to these twins. The history of consanguinity of the parents, the occurrence in twins, and the results of HLA typing suggest a genetic factor in the etiology of Takayasu's disease.

78-7-05

EMHG-23-1285

\section{SYSTEMIC LUPUS ERYTHEMATOSUS IN TWINS}

O.A. Jurgenssen, G. Kolarz, E. Pichler, and O. Scherak

University-Kinderklin., Vienna, Austria

Klinische Paediatrie (1978) 190:412-417

A report is given of systemic lupus erythematosus (SLE) in monozygotic twins. One sister developed Coombspositive haemolytic anaemia at the age of 11 years and suffered from five haemolytic crises over a period of 8 months. SLE could not be proven at that time, but following a 3-year symptom-free period, characteristic clinical and immunological evidence of SLE became manifest. The second sister developed classical SLE at the age of 15 years. Clinical, immunological, etiological and therapeutic aspects of SLE are being discussed.

78-7-06

EMPPS-40-679

\section{CONTRIBUTION TO APLASIA CUTIS}

G. K. Hinkel

Abt. Neonatol. Kinderklin., Med. Akad. Carl Gustav Carus, Dresden, German Democratic Republic Kinderaerztliche Praxis (1978) 46:231-235

A report is presented on the observation of a generalized form of an aplasia cutis in a premature triplet with spontaneous cure.

78-7-07

EMHG-22-1535

\section{NASAL DEFECTS IN IDENTICAL TWINS}

\section{F.S. DiMauro}

Atlantic City Medical Center, Somer's Point, New Jersey

Ear, Nose, and Throat Journal (1978) 57:226-228

Suggested causes of nasal septal deformity have ranged from nasal and postnasal trauma to different growth rates of septum and nasal bones. Genetic factors have also been implicated. The purpose of this article is to present a case that might have such a genetic basis. 


\title{
TWIN PREGNANCY IN A PATIENT WITH GLANZMANN DISEASE (CONGENITAL
} THROMBASTHENIA)

\author{
H. Riedel, M. Barthels, E. Lingelbach, and H. Weitzel
}

Abt. I, Frauenklin. MHH, Hannover, Federal Republic of Germany

Geburtshilfe Frauenheilkunde (1978) 38:285-288

Report on a $30 \mathrm{yr}$ old primigravida with a family history of bleeding and a personal history of nasopharyngeal bleeding since age 4 and severe menorrhagia since her menarche; first seen at 20 wk gestation with nasopharyngeal bleeding and a twin pregnancy. The patient was found to have Glanzmann's disease (congenital thrombasthenia) with an excessive lack of factor XIII. Ambulatory treatment with packed cell transfusions until 35 wk gestation. The thromboelastogram did not improve with transfusions of platelet concentrates. In-patient treatment from 35 to $37 \mathrm{wk}$ gestation, no vaginal bleeding throughout the pregnancy. Elective Caesarian hysterectomy at 37 wk gestation with 10 units fresh blood, 3 units platelet concentrate and 10 ampules factor XIII concentrate in readiness. Delivery of twin girls 3180 and $3050 \mathrm{~g}$ without signs of Glanzmann's disease. Treatment of the maternal bleeding by replacement. Factor XIII $80 \%$ of the normal 8 wk postpartum. This appears to be the first case of twin pregnancy in the presence of Glanzmann's disease and the fourth case in the world literature.

78-7-09

EMOG-36-355

\section{THE LANDRY-GUILLAIN-BARRE SYNDROME AND PREGNANCY}

G. Ahlberg and G. Ahlmark

Department of Medicine. Falu Hospital, Falun, Sweden

Acta Obstetricia et Grnecologica Scandinavica (1978) 57:377-380

The Landry-Guillain-Barre syndrome is considered rare in connection with pregnancy. In mild cases the course of the pregnancy is unaffected. In severe cases, with respiratory depression and bulbar symptoms. especially during late pregnancy, the syndrome entails an increased risk to both mother and fetus. Therapeutic abortion or cesarean section are not considered to be indicated. A pregnant woman developed the disease during the final trimester and gave birth to premature twins during respirator treatment. The mother and the infants survived.

78-7-10

EMHG-22-2350

FRAGILITY AND SPIRALIZATION ANOMALIES OF THE CHROMOSOMES IN THREE CASES, INCLUDING FRATERNAL TWINS, WITH FANCONI'S ANEMIA, TYPE ESTREN DAMESHEK

W. Schmid and G. Fanconi

Division of Medical Genetics, Department of Pediatrics, University of Zürich

Cytogenetics and Cell Genetics (1978) 20:141-149

Fraternal twins, offspring of consanguineous parents, developed pancytopenia, the boy at 7 , the girl at 12 years of age. A third patient became anemic at 3 years. All three are free of associated malformations. In blood cultures the incidence of chromatid breaks. exchanges, and chromosome-type aberrations was elevated to $24 \%$, $18 \%$, and $28 \%$. respectively. In addition, in a low number of mitotic cells unusual observations, pointing to profound disturbances of chromosome structure, were made. It is suggested that these patients have a genetic defect impairing the normal process of mitotic chromosome condensation and decondensation.

78-7-11

\section{TRISOMY 8 MOSAICISM SYNDROME. REPORT OF MONOZYGOTIC TWINS}

EMPPS-40-2730

P.G: Reyes, L.Y.F. Hsu, L. Strauss, et al.

Division of Medical Genetics, Department of Pediatrics, Mt. Sinai School of Medicine, New York

Clinical Genetics (1978) 14:90-97

Monozygotic twins were born with the phenotypical appearance of the trisomy 8 syndrome. The first twin, a stillborn, had autopsy findings suggestive of trisomy 8 syndrome. Cultured lymphocytes and skin fibroblasts of the second, liveborn twin, showed trisomy 8 . While the lymphocyte culture showed $46 / 47,+8$ mosaicism, with normal cells predominating, skin fibroblasts yielded only cells with trisomy 8 . Bone marrow preparation showed only normal cells, $46, \mathrm{XY}$. Repeat lymphocyte culture at age 14 months showed a reduced number of trisomy 8 cells. The authors would like to emphasize the importance of cytogenetic studies in early infancy, 
using both peripheral lymphocyte and skin fibroblast cultures, to increase the chance of detecting chromosomal abnormalitics.

78-7-12

EMPPS-40-455

\section{TRISOMY 21 IN ONE OF TWIN FETUSES}

R.H. Heller and L.S. Palmer

Department of Gynecology and Obstetrics, Johns Hopkins University School of Medicine, Baltimore

Pediatrics (1978) 62:52-53

Both the detection of twins and the successful execution of a double amniocentesis pose significant technical problems in prenatal diagnosis. A case is reported in which one of twin fetuses had trisomy 21 and the other was chromosomally normal. Following counseling, the family chose to continue the pregnancy. At term, the mother was delivered of a healthy infant and a severely macerated fetus with stigmata suggestive of Down's syndrome.

78-7-13

EMPPS-40-3124

\section{DOWN SYNDROME IN TWO OF THREE TRIPLETS}

R.M. Liberfarb, L. Atkins, and L.B. Holmes

Genetics Unit, Children`s Service, Massachusetts General Hospital, Boston

Clinical Genetics (1978) 14:26I-264

This is my first report to the authors' knowledge of trisomy 21 in two members of a set of triplets. The two with Down syndrome are monozygous; the other triplet is not identical. These triplets were born to a 22-yrold woman in whose family there have been six sets of twins (four like-sex) since 1775. Neither parent has any chromosomal abnormality. Zygosity estimates in the triplets are derived from studies of red blood cell antigens and HLA typing. Twinning has been reported in association with many different chromosome abnormalities. It has been suggested that the incidence of Down syndrome among twins is significantly higher than among singletons. It seems likely that some families have a heritable predisposition to both twinning and chromosome abnormalities.

78-7-14

EMHG-22-843

\section{RETINOBLASTOMA IN A MICROPHTHALMIC EYE}

\section{Axelsen}

Aarhus Kommunehospital, University of Aarhus, Denmark

Ophthalmologica (1978) 176:24-26

A case of simultaneous occurrence of microphthalmus and retinoblastoma in an eye removed from a 1-yearold monozygote twin with bilateral retinoblastoma, is reported. The other eye was of normal size, and was treated with irradiation (local application of Stallard disc). This case seems to be the first one published showing that one cannot be sure of the absence of tumours in small eyes although it is extremely rare. The patient's twin sister was examinated shortly after. She also had bilateral retinoblastoma, but no microphthalmus. One eye was enucleated and showed regressed retinoblastoma, the other treated with irradiation.

78-7-15

EMPPS-40-325

\section{CONGENITAL HERPES SIMPLEX VIRUS, TYPE 2, BILATERAL ENDOPHTHALMITIS}

\section{Yanoff and M.I. Allman}

Department of Ophthalmology, University of Pennsylvania, Philadelphia

Transactions of the American Ophthalmological Society (1978) 75:325-338

A set of dizygotic twins, both born prematurely, developed herpes simplex encephalitis shortly after birth. The second twin had unilateral keratoconjunctivitis and bilateral endophthalmitis and subsequently died from disseminated herpes infection. Herpes simplex, type 2, was isolated from conjunctiva of both eyes, cerebrospinal fluid, nasopharynx and trachea. Histologic examination of the eyes revealed bilateral endophthalmitis with a necrotizing retinitis. Intranuclear inclusion bodies were demonstrated by light microscopy in the retina, choroid and iris, and virus particles were demonstrated by electron microscopy in the retina. The other twin recovered from a much milder disseminated herpes simplex infection without apparent ocular involvement. During pregnancy, the mother had vaginitis which was suspected, but not documented, as being herpetic in origin. The father was diagnosed as having a penile infection caused by herpes simplex. 
78-7-16

\title{
RETINAL DYSTROPHIES ASSOCIATED WITH PERIPHERAL RETINAL VASCULOPATHY
}

EMO-33-562

\author{
W.S. Grizzard, A.F. Deutman, and A.J.L.G. Pinckers
}

Institute of Ophthalmology, University of Nijmegen, Netherlands

British Journal of Ophthalmology (1978) 62:188-194

A pair of identical twins with cone-rod dystrophy and 1 patient with dominant retinitis pigmentosa are reported who had a peculiar vascular retinopathy characterised by perivenous accumulation of fluorescein in the temporal periphery. Other retinal dystrophies associated with leaking retinal vessels are discussed.

78-7-17

EMHG-22-802

\section{CENTRAL CORE DISEASE IN ONE OF IDENTICAL TWINS}

\author{
M.E. Cohen, P.K. Duffner, and R. Heffner
}

Division of Child Neurology and Neuropathology, State University of New York School of Medicine,

Buffalo

Journal of Neurology. Neurosurgery and Psvchiatry (1978) 41:659-663

A case of central core disease in one of identical twins is presented. The light and electron microscopic pathology is reviewed. We believe that these entities are not genetic in this sibship and may be an example of isolated maturational arrest of non-specific aetiology.

78-7-18

EMDV-33-3666

\section{MALIGNANT MELANOMA IN TWINS}

\author{
R. Shafir and H. Tsur \\ Department of Plastic Surgery, Chaim Sheb Medical Center, Tel-Hashomer, Israel \\ British Journal of Plastic Surgery (1978) 31:355
}

The hereditary form of malignant melanoma has been well documented in the literature, mainly by the report of Anderson and Bordelon. Reports of sisters with melanoma, and of parents and their offspring, as well as other combinations in familial melanoma, have become more frequent. Malignant melanoma in twins has also been recorded, but only in 2 pairs. The present report concerns identical twin sisters, born in 1946 .

78-7-19

EMIST-20-872

\section{GENETICS OF SV40 T-ANTIGEN EXPRESSION: STUDIES OF TWINS, HERITABLE SYNDROMES AND CANCER FAMILIES}

\author{
W.A. Blattner, A.S. Lubiniecki, J.J. Mulvihill, et al. \\ Environmental Branch. National Cancer Institute, Bethesda, Maryland \\ International Journal of Cancer (1978) 22:231-238
}

\begin{abstract}
Susceptibility of human skin fibroblasts to SV40 virus infection has been suggested as a marker of cancer risk. To evaluate the role of heritable factors in the regulation of SV40 T-antigen, fibroblasts from 9 pairs of identical twins and 129 members of cancer-prone families, including 16 with cancer, were tested in a 3-day immunofluorescence assay. In the twin study, the variance of $\mathrm{T}$-antigen values was significantly less in identical than in fraternal or non-twin sibs, suggesting a heritable component in the regulation of SV40 infection. In the families, T-antigen values of parents and children were compared to models of Mendelian inheritance. At least three modes of inheritance-autosomal dominant, recessive, and X-linked-were observed. The distribution on offspring values compared to those of their parents suggested that interaction of multiple genetic factors influences the T-antigen value in individual patients. With the exception of Fanconi's anemia, the values for patients with cancer or predisposing syndromes were not uniformly elevated. The utility of this assay as a marker of cancer risk appears limited because of the complexity of factors that influence T-antigen expression in individual cases.
\end{abstract}


78-7-20

EMHG-22-1715

\section{HISTOLOGICALLY PROVED BASAL CELL CARCINOMAS IN IDENTICAL TWINS}

K. Liddell

District General Hospital, Eastbourne, Great Britain

British Medical Journal (1978) 2/6130:97

Two twin sisters developed a basal cell carcinoma at virtually the same time, in an almost identical atypical site (the back) and with an unusual morphology suggesting that they had inherited a localised susceptibility to the development of basal cell carcinoma. They had no other manifestations of Gorlin's syndrome and had also not simply inherited a generalised increase in susceptibility to sunlight. The identical twin sisters closely match the male identical twins described by Oettle in their development of basal cell carcinoma and possibly they inherited a biochemical defect underlying the development of the carcinoma, although the precise localisation effect is bizarre.

78-7-21

EMHG-23-545

\section{CARCINOMA OF THE GASTRIC ANTRUM IN IDENTICAL TWINS}

D.J. Ellis

Queen Elizabeth Hospital, Birmingham, Great Britain

Clinical Oncology (1978) 4:299-302

This paper describes identical twins aged 46 who developed carcinoma of the gastric antrum at the same time. A brief review of familial and genetic factors in the aetiology of gastric carcinoma is included.

78-7-22

EMHG-23-2397

\section{AUTO-IMMUNE ADDISON'S DISEASE IN IDENTICAL TWINS}

J.P. Simmonds and J. Lister

King Edward VII Hospital, Windsor, Great Britain

Postgraduate Medical Journal (1978) 54:552-554

Identical male twins are described, one of whom presented with clinical symptoms of Addison's disease whereas the other was shown to have a deficient adrenal cortical response to stimulation tests. Both had positive adrenal cortex antibodies.

78-7-23

EMHG-23-1084

MONOZYGOTIC TWINS DISCORDANT FOR DUANE'S RETRACTION SYNDROME

A.L. Rosenbaum and S.J. Weiss

Jules Stein Eye Institute, UCLA School of Medicine, Los Angeles

Journal of Pediatric Ophthalmology and Strabismus (1978) 15:359-361

Monozygotic twin boys discordant for the occurrence of Duane's retraction syndrome are presented. This appears to be the first report of such discordance between monozygotic twins. The theoretic problems which this situation poses for the explanation of the acquisition of Duane's retraction syndrome is discussed.

78-7-24

EME-14-378

\section{CEPHALOTHORACIC LIPODYSTROPHY WITH HYPOCOMPLEMENTEMIC RENAL DISEASE: DISCORDANCE IN IDENTICAL TWIN SISTERS}

D.M. Bier, J.J. O'Donnell, and S.L. Kaplan

Department of Pediatrics, University of California, San Francisco

Journal of Clinical Endocrinology and Metabolism (1978) 46:800-807

This report describes the occurrence of cephalothoracic lipodystrophy in one of 7-yr-old identical twin sisters. The affected twin had classical loss of sc fat from her face, upper arms, and trunk as well as associated hypocomplementemia, microscopic hematuria, and a borderline oral glucose tolerance test without hyperinsulinism. The unaffected twin had a normal urinalysis, serum complement, and oral glucose tolerance. Both twins, when challenged iv with LRH or TRH, showed appropriate FSH and LH or TSH and PRL responses, respectively. This report, in conjunction with another similar twin pair recently described in the German literature, makes a simple, single gene genetic etiology untenable and supports the view that cephalothoracic lipodystrophy is an acquired disease. 


\section{TWIN STUDY OF MULTIPLE SCLEROSIS: AN EPIDEMIOLOGIC INQUIRY}

A.R. Bobowick, J.F. Kurtzke, J.A. Brody, et al.

Epidemiology Branch, National Institute of Neurological Communicative Disorders Stroke, NIH, Bethesda, Maryland

Neurology (1978) 28:978-987

The National Research Council Twin Registry comprises 16,000 pairs of white male twins, both members of which had been in military service, mainly in World War II. All their available military and Veterans Administration records and their responses to a 1965 to 1970 NRC questionnaire have been coded as to disease. Upon review the authors found 16 cases of multiple sclerosis (MS) among 15 pairs of twins, for an age-specific prevalence rate of 51 per 100,000 veterans aged 43 to 53 -about half the expected frequency. Of the 15 sets, three sets refused cooperation and three were unavailable for study. Nine sets were examined and interviewed together with the mother. One of five monozygotic twin pairs was concordant for MS and in another the cotwin of an MS case had had a solitary episode of retrobulbar neuritis; all others were discordant. There were more definable environmental events (as noted below) among the affected twins than among the unaffected cotwins. The greatest excess was within the 20 years before onset. Summing events across the four 5 -year periods before onset, among the $10 \mathrm{MS}$ versus the eight non-MS individuals, there were 5:1 instances of trauma, 8:2 of operation, 7:1 of ether anesthesia, 7:1 of allergy, 10:5 of infections, and 9:0 of animal exposure. Summing these same events within each 5-year period, the MS:control ratios were 9:1, 10:2, 12:3, and 15:4, respectively, for 0 to 4,5 to 9,10 to 14 , and 15 to 19 years before onset.

78-7-26

\section{CONGENITAL TUBERCULOSIS IN A TWIN OF IMMIGRANT PARENTAGE}

EMOG-36-2377

M.R. Dische, C. Krishnan, R. Andreychuk, and M.W. Fujiwara

Department of Pathology, Hospital for Sick Children, Toronto

Canadian Medical Association Journal (1978) 119:1068-1070

This paper reports observations on an infant with congenital tuberculosis born in Canada to a recently arrived immigrant whose infection was proven after she gave birth.

78-7-27

EMHG-23-183

JUVENILE NEPHRONOPHTHISIS, CONGENITAL HEPATIC FIBROSIS AND RETINAL HYPOPLASIA IN TWINS

V. Delaney, J. Mullaney, and E. Bourke

Department of Medicine, Trinity College, Dublin

Quarterly Journal of Medicine (1978) 47:28I-290

Juvenile nephronophthisis has been recognized recently as an important cause of chronic renal failure in childhood and adolescence. This report described clinical and morphological findings in monozygotic twins in whom the triad of juvenile nephronophthisis, congenital hepatic fibrosis and retinal hypoplasia coexisted. The findings are discussed in relation to previous reports of nephronophthisis associated with either retinal abnormalities or congenital hepatic fibrosis. The concurrence of similar ocular and hepatic anomalies with the other cystic kidney diseases, polycystic disease and medullary sponge kidney disease is reviewed. A spectrum of oculo-hepatorenal syndromes is identified with many interrelated features which suggest a shared basic aetiology.

78-7-28

EMHG-22-1963

\section{PULMONARY ABNORMALITY AND ALPHA -ANTITRYPSIN HETEROZYGOTE DEFICIENCY IN A WORKING POPULATION}

F. Girard, F. Aug, M. Camara, et al.

Unité Recherches Physiopathologie Respiratoire INSERM, Vandoeuvre, France

Bulletin Européen de Physiopathologie Respiratoire (1978) 14:11-22

Subjects with severe alpha,-antitrypsin $\left(\alpha_{1} \mathrm{AT}\right)$ deficiency related to the homozygous phenotype $\mathrm{Pi} Z \mathrm{Z}$ are prone to an emphysema, but it is not certain whether the same is true for heterozygous deficient subjects ( $\mathrm{Pi}$ MS, Pi MZ). This study was made in order to investigate a link between the presence of a heterozygous phenotype and the appearance of clinical and functional lung abnormalities. We determined the $\alpha_{1}$ AT serum concentration in 1.525 subjects from a general population and established the phenotypes of the deficient 
patients. The 66 heterozygous subjects thus identified (39 Pi MS, 24 Pi MZ, 3 Pi SZ) were divided up according to tobacco consumption, period of examination and age, and compared with 66 control $\mathrm{Pi} \mathrm{M}$ subjects from the same population. The 132 subjects were examined clinically (ECSC questionnaire and lung auscultation) and functionally (static lung volumes, airway resistances, flow-volume curves, carbon monoxide transfer factor). When the heterozygous group is compared globally with its control group, no significant difference is discernible, either in terms of symptoms or of functional signs. Likewise, the examination of subgroups of $\mathrm{Pi} \mathrm{MS}$ and $\mathrm{Pi}$ $\mathrm{MZ}$ subjects showed no clinical or functional differences when compared with their respective control groups.

78-7-29

EMHG-22-2264

\section{MONOZYGOTIC TWINS WITH PRESUMED METACHROMATIC LEUKODYSTROPHY. ACTIVITY OF ARYLSULFATASE A IN SERUM OF PATIENTS AND FAMILY}

T. Hashimoto, H. Minato, Y. Kuroda, et al.

Department of Pediatrics, Tokushima University School of Medicine, Japan

Archives of Neurology (1978) 35:689-691

Arylsulfatase A (ASA) activity in urine and serum was assayed on two 21-month-old monozygotic twins with presumed metachromatic leukodystrophy (MLD), their parents, and kin. The patients showed a marked reduction in ASA activity in both urine and serum. The twins' parents and $11 \mathrm{kin}$, a total of 13 persons, were examined for ASA activity in serum, but it was not possible to delineate heterozygous carriers of MLD by the present study. The assay of ASA activity in serum promises to be useful to diagnosis of MLD.

78-7-30

EMHG-23-142

COAGULATION FACTOR DEFICIENCY APPARENTLY RELATED TO THE FITZGERALD TRAIT: THE FIRST CASES IN JAPAN

H. Hayashi, H. Koya, K. Kitajima, and I. Kimura

Department of Internal Medicine, University Medical School, Okayama, Japan

Acta Medica Okavama (1978) 32:81-83

A blood coagulation deficiency was found at the contact phase in identical Japanese female twins. Of the four possible factors involved, Factor XI or XII can be ruled out according to cross-correction studies. The problem factor was probably not Fletcher factor, because the abnormal partial thromboplastin time was not significantly shortened by increasing the incubation period of plasma with kaolin. The deficiency is most likely due to the lack of Fitzgerald factor.

78-7-31

EMHG-23-795

MONOZYGOUS TWINS DISCORDANT FOR AMYOTROPHIC LATERAL SCLEROSIS

M. Jokelainen, J. Palo, and J. Lokki

Department of Neurology, University of Helsinki, Finland

European Neurology (1978) 17:269-299

A pair of identical female twins were discordant for amyotrophic lateral sclerosis. The affected twin was not breast-fed; was bitten by a poisonous snake, and was operated on for struma. She had more infections than her sister but no fractures. Her plasma insulin response to glucose loading was also higher. The twins lived separated in their early childhood.

78-7-32

\section{OSTEOGENESIS IMPERFECTA IN ONE OF TWINS. CASE REPORT}

EMHG-23-1043

G.S. Firlit and W.H. Bunch

USA

Clinical Orthopaedics and Related Research (1978) 135:39-41

This is a report of a 5-year-old girl with osteogenesis imperfecta, an uncommon abnormality considered to encompass several distinct disorders and biochemically classified as a connective tissue disease. Affected individuals, in the more severe form of the disease, often die in utero or shortly thereafter secondary to birth trauma. The patient was one of dizygotic twins discordant for osteogenesis imperfecta tarda inherited as an autosomal dominant trait. 


\title{
DIABETES IN IDENTICAL TRIPLETS
}

\author{
M.W. McKendrick and M.G. Fitzgerald
}

Diabetes Clinic, General Hospital. Birmingham, Great Britain

British Medical Journal (1978) 1/6111:482

The subject of diabetes mellitus in identical twins has been well studied. It has been shown that almost all twins diagnosed over the age of 40 are concordant for diabetes and half have a diabetic parent. The average time between diagnosis in such twins is 2.6 years and no association has been shown with any HLA type or with the presence of islet-cell antibody. The triplets fit well into this pattern. They are typical maturity-onset diabetics and concordance has been shown, although there is no family history of diabetes. They have none of the HLA types associated with juvenile-onset diabetes (B8 BWI5 B 18) and, although there is an association between HLA-A3 and haemochromatosis, their serum iron concentration and total iron-binding capacity are normal. Perhaps surprisingly. there were 12 years between diagnosis of the first and last triplets, but the onset of diabetes is notoriously difficult to date. The first triplet diagnosed was asymptomatic and may not have developed symptoms for some years. The last triplet was appreciably lighter at diagnosis than the other two and this may have delayed the onset of symptoms; indeed, the finding of micro-aneurysms at the time of diagnosis does suggest that he had been diabetic for considerably longer than his symptoms of two months suggested. The strong family history and high rate of concordance for diabetes found in the twin studies reinforce the view that genetic factors are dominant in the aetiology. The failure to demonstrate association with HLA type suggests genetic heterogeneity. In summary, we report identical triplets concordant for diabetes for the first time and show them to fit into the pattern expected from the identical twin studies.

78-7-34

EMHG-23-953

\section{URTICARIA PIGMENTOSA IN IDENTICAL TWINS}

\author{
A.S. Rockoff
}

Department of Pediatrics, Mt. Sinai Hospital, Hartford, Connecticut

Archives of Dermatologv (1978) 114:1227-1228

The authors report an eighth set of identical twins who both have UP, and discuss the genetics of this condition.

\section{CLINICAL COURSE OF CONGENITAL TOXOPLASMOSIS IN DIZYGOTIC TWINS}

\author{
A. Statz, D. Wenzel, and G. Heimann
}

University Kinderklin., Köln, Federal Republic of Germany

Klinische Paediatrie (1978) 190:599-602

The case presented deals with the clinical course of a congenital toxoplasmosis in dizygotic twins. The variability of the clinical course was proved by the fact that one of the twins remained unaffected with clinical signs and the condition was detected only by the conversion of the seroreactions. The second twin showed the picture of an acute meningoencephalitis resulting in a neurological defect syndrome. The reasons for the differing clinical course which are more pronounced in dizygotic twins than monozygotic, remain unknown.

\section{CONGENITAL ESOPHAGEAL ATRESIA WITH TRACHEOESOPHAGEAL FISTULA IN} IDENTICAL TWINS

\author{
R. Ohkuma
}

Department of Surgery, National Hospital, Shimonoseki, Japan

Journal of Pediatric Surgery (1978) 13:361-362

This is a report of the seventh case of esophageal atresia in both members of a pair of identical twins. 
79-7-01

$\alpha_{1}$-ANTITRYPSIN DEFICIENCY IN TWINS AND PARENTS-OF-TWINS

EMHG-22-2738

\author{
J. Lieberman, N.O. Borhani, and M. Feinleib
}

Respiratory Diseases Section, UCLA, Los Angeles

Clinical Genetics (1979) 15:29-36

Serum-trypsin-inhibitory-capacity (STIC) and $\alpha_{1}$-antitrypsin (AAT) genotypes were evaluated in 83 twins and 112 paired parents-of-twins. An increased prevalence (17.0-21.9\%) of intermediate AAT deficiency (STIC $<0.95$ units $/ \mathrm{ml}$ ) was detected in both of these groups as compared to a prevalence of $4.1 \%$ in 1,841 healthy controls. $\mathrm{PiS}$ and PiZ molecular variants of AAT were also found more frequently in the twin and parent groups, but this was not statistically significant. Low levels of protease inhibition may enhance fertility and a tendency towards twinning, since proteolytic enzymes are involved in fertilization of ova by sperm and in gametogenesis. Increased fertility and twinning may be heterozygous advantages for AAT deficiency.

79-7-02

EMPPS-41-3536

\title{
CONCORDANT LEUKEMIA IN IDENTICAL TWINS
}

J. Braemswig, G. Schellong, and W. Voss

Abt. Hematologie und Onkologie, University Kinderklin., Münster, Federal Republic of Germany Klinische Paediatrie (1979) 191:140-144

We report female monozygotic twins who developed acute lymphoblastic leukemia at the age of $5 \mathrm{l} / 2 \mathrm{yr}$. The diagnosis in the first twin was made after pallor, lethargy, and petechiae developed. The diagnosis in the second twin was made two days later when a whole blood count was taken. The lymphoblasts of both patients showed with the exception of the PAS-reaction identical morphological, cytochemical, and immunological results. The PAS-reaction was positive in 55\% of the lymphoblasts in one twin, negative in the lymphoblasts of the other twin. Both patients are in continuous complete remission $14 \mathrm{mth}$ after diagnosis. The risk of leukemia is high in the other monozygotic twin when one of the twins has already developed leukemia. In the literature it is estimated to be 1:5. The diagnosis after the second year of life is rarely made at the same time. There is only one previous report of this occurring in a case of acute myeloblastic leukemia in $41 / 2 \mathrm{yr}$ old monozygotic twins.

79-7-03

EMPPS-41-3254

\section{THE ROLE OF GENETIC FACTORS IN THE ETIOLOGY OF WILMS' TUMOR. TWO PAIRS OF MONOZYGOUS TWINS WITH CONGENITAL ABNORMALITIES (ANIRIDIA; HEMIHYPERTROPHY) AND DISCORDANCE FOR WILMS' TUMOR}

H.S. Maurer, T.W. Pendergrass, W. Borges, and G.R. Honig

Department of Pediatrics, Northwestern University Medical School, Child Memorial Hospital, Chicago

Cancer (1979) 43:205-208

Wilms' tumor was diagnosed in two children each of whom has an identical twin. In one of the pairs of twins the aniridia syndrome with psychomotor retardation was present in both children, but Wilms' tumor was found in only one. In the other twins hemihypertrophy as well as Wilms' tumor were identified in one child, whereas neither of these abnormalities was present in her twin sister. These findings lend support to a hypothesis that the development of Wilms' tumor requires the occurrence of two successive mutational events, one of which may be a germinal mutation. The presence of aniridia, hemihypertrophy, or other associated congenital abnormalities may aid in distinguishing between hereditary and sporadic forms of Wilms' tumor. 